\title{
Ventral Subicular Interaction With the Hypothalamic Paraventricular Nucleus: Evidence for a Relay in the Bed Nucleus of the Stria Terminalis
}

\author{
WILLIAM E. CULLINAN, JAMES P. HERMAN, AND STANLEY J. WATSON \\ Mental Health Research Institute, University of Michigan, Ann Arbor, Michigan 48109-0720 \\ (W.E.C., S.J.W.) and Department of Anatomy and Neurobiology, University of Kentucky \\ Medical Center, Lexington, Kentucky 40536-0084 (J.P.H.)
}

\begin{abstract}
The axonal projections of the ventral subiculum to the bed nucleus of the stria terminalis (BST) were examined in the rat with the anterograde neuronal tracer Phaseolus vulgarisleucoagglutinin (PHA-L). Axons originating in the ventral subiculum coursed to the BST through either the fimbria-fornix, or a pathway involving the stria terminalis via the amygdala. Ventral subicular axons gave rise to dense terminal networks that were preferentially distributed in medial and ventral subregions of the BST. The distribution of subicular fibers and terminals was examined in relation to BST neurons that project to the hypothalamic paraventricular nucleus (PVN). In these cases, discrete iontophoretic injections of the retrograde tracer Fluoro-gold were made in the PVN, with PHA-L delivered to the ipsilateral ventral subiculum. An immunocytochemical double-labeling protocol was then employed for the simultaneous detection of PHA-L and Fluoro-gold, and provided light microscopic evidence for subicular input to PVN-projecting cells located within the BST.

In a second series of experiments, the $\gamma$-amino butyric acid (GABA)ergic nature of the BST was examined by in situ hybridization histochemistry for detection of transcripts encoding $\mathrm{GAD}_{67}$ mRNA. The studies revealed that a high proportion of BST neurons express $\mathrm{GAD}_{67}$ transcripts. Also, experiments combining Fluoro-gold tracing with $\mathrm{GAD}_{67}$ in situ hybridization suggested that a proportion of PVN-projecting neurons in the BST are GABAergic. Taken together, the results of these sets of studies suggest that the inhibitory influences of the hippocampus on the PVN might be relayed through specific portions of the BST. These findings may have important implications for our understanding of the neural regulation of the hypothalamic-pituitary-adrenal axis. 1993 Wiley-Liss, Ine.
\end{abstract}

Key words: subiculum, anterograde tracing, retrograde tracing, in situ hybridization, glutamic acid decarboxylase mRNA

The neurons of the medial parvicellular division of the hypothalamic paraventricular nucleus (mpPVN) represent the origin of a final common pathway involved in activation of the hypothalamic-pituitary-adrenal (HPA) axis; these cells, which synthesize and release corticotropin-releasing hormone (CRH), arginine vasopressin (AVP), and other secretagogues are responsible for a cascade of events culminating in the adrenocorticotropic $(\mathrm{ACTH})$-mediated release of glucocorticoids from the adrenal cortex. Glucocorticoid levels are appropriately maintained by inhibitory influences exerted at multiple levels, including the anterior pituitary, the PVN, and additional brain areas (Keller-Wood and Dallman, '84; Kovacs et al., '86; Sawchenko, '87). A brain region strongly implicated in the inhibitory control of the
HPA axis is the hippocampus. Hippocampal stimulation has been reported to inhibit median eminence-projecting neurons in the PVN (Saphier and Feldman, '87), to reduce plasma corticosteroid levels (Mandell et al., '62; Rubin et al., '66; Dunn and Orr, '84), and to inhibit stress-induced corticosterone secretion (Endröczi et al., '59; DuPont et al., '72). Other studies have demonstrated that hippocampal ablation, or transsection of its major efferent pathway, the fimbria-fornix, results in elevated ACTH levels in the hypophyseal portal system (Sapolsky et al., '89), and glucocorticoid hypersecretion basally or in response to stress (Fendler et al,, '61; Knigge, '61; Feldman and Conforti, '80;

Accepted January 29, 1993. 
Wilson et al., '80; Margariños et al., '87; Herman et al., ' $89 \mathrm{~b}$ ). Fischette et al. ('80, '81) first focused attention on a possible role for the ventral subiculum in glucocorticoid regulation, demonstrating that fimbria-fornix lesions that disrupt ventral subicular efferents altered the circadian rhythmicity of plasma corticosterone levels. In addition, recent evidence has indicated that hippocampal ablations or selective fimbria-fornix lesions result in induction of $\mathrm{CRH}$ and AVP mRNA in the mpPVN (Herman et al., ' $89 \mathrm{~b}$, '92). The fact that the hippocampus contains the highest brain levels of type I and type II glucocorticoid receptors and their mRNAs has further implicated this structure in the inhibitory control of HPA function (McEwen et al., '68; Sapolsky et al., '83; Reul and de Kloet, '85, '86; Arriza et al., '88; Van Eekelen et al., '88; Herman et al., '89a; Sousa et al., '89).

The neural pathways by which hippocampal inhibitory influences are conveyed to the PVN have remained unclear. Anterograde neuronal tracing studies have suggested that the hippocampus lacks significant direct input to the PVN (Swanson and Cowan, '77; Köhler, '90), and hippocampal output is generally thought to be excitatory (Wallas and Fonnum, '80; Finch et al., '86). These findings suggest the existence of one or more neuronal relays between the hippocampal formation and the PVN. One candidate region for this function is the bed nucleus of the stria terminalis (BST) (Sawchenko and Swanson, '83b; Swanson, '86; Herman et al., ' $89 \mathrm{c}$ ). Anterograde and retrograde neuronal tract-tracing studies have demonstrated that the BST receives input from the ventral subiculum (Swanson and Cowan, '77, '79; Meibach and Siegel, '77; Krettek and Price, '78; Weller and Smith, '82), and a BST projection to the PVN has been similarly confirmed (Swanson and Cowan, '79; Silverman et al., '81; Sawchenko and Swanson, '83a;
Grove, '88). Recently the efferent projections of the ventral subiculum have been described in experiments utilizing the sensitive anterograde tracer Phaseolus vulgaris-leucoagglutinin (PHA-L) (Köhler, '90; Witter and Groenewegen, '90), although little information was reported concerning inputs to the BST. A major focus of the present investigation was to examine both the precise relationship between the ventral subiculum and this nucleus, and whether subicular fibers might contact PVN-projecting neurons located in the BST.

A second series of experiments was undertaken to determine whether the BST projection to the PVN contains the neurotransmitter $\gamma$-amino butyric acid (GABA). A number of studies have implicated GABAergic mechanisms in the negative control of HPA activity (Makara and Stark, '74; Jones et al., '76; Acs and Stark, '78; Tappaz et al., '82; Plotsky et al., '87b; Calogero et al., '88), although the site(s) of GABA action was not determined. The BST is known to contain a rich population of GABAergic neurons (Mugnani and Oertel, '85; Ferraguti et al., '90; Erlander et al., '91), although whether such neurons are among those that project to the PVN has not been examined to date. To address this question, a separate series of experiments was undertaken utilizing the retrograde neuronal tracer Fluorogold, in combination with in situ hybridization histochemistry for detection of mRNA transcripts encoding glutamic acid decarboxylase (GAD), the GABA-synthesizing enzyme.

\section{MATERIALS AND METHODS Anterograde and retrograde neuronal tracing}

Twenty-five male Sprague-Dawley rats weighing between 275 and $325 \mathrm{~g}$ were included. Animals were anesthetized

Abbreviations

\begin{tabular}{|c|c|}
\hline ac & anterior commissure \\
\hline $\mathrm{AD}$ & anterodorsal thalamic $\mathrm{n}$. \\
\hline AHA & anterior hypothalamic area \\
\hline AHiPM & amygdalohippocampal area, posteromedial \\
\hline & anterior lateral division, $\mathrm{BST}^{\prime}$ \\
\hline AM & anteromedial thalamic $\mathrm{n}$. \\
\hline am & anterior medial division, BST \\
\hline Arc & arcuate $n$. \\
\hline BL & basolateral amygdaloid $\mathrm{n}$. \\
\hline BM & basomedial amygdaloid $n$. \\
\hline BST & bed nucleus of stria terminalis \\
\hline BSTIA & bed nucleus of stria terminalis, intraamyg. div. \\
\hline CA1 & field CAl of Ammon's horn \\
\hline CeI, & central anygdaloid n., lateral \\
\hline $\mathrm{CeM}$ & central arnygdaloid n., medial \\
\hline $\mathrm{Co}$ & cortical amygdaloid n. \\
\hline $\mathrm{CP}$ & caudate putamen \\
\hline dl & dorsal lateral division, BST \\
\hline DMH & dorsomedial thalamic $n$. \\
\hline Ent. & entorhinal cortex \\
\hline f & fornix \\
\hline fi. & fimbria \\
\hline GP & globus pallidus \\
\hline HDB & horizontal limb of diagonal band $n$. \\
\hline IAM & interoanteromedial thalamic $\mathrm{n}$. \\
\hline ic & internal capsule \\
\hline LA & lateral amygdaloid $n$. \\
\hline $\mathrm{LH}$ & lateral hypothalamus \\
\hline $\mathrm{LPO}$ & lateral preoptic area \\
\hline LSI & lateral septal n., intermediate \\
\hline LV & lateral ventricle \\
\hline meht & medial corticohypothalamic tract \\
\hline $\mathrm{MD}$ & mediodorsal thalamic $n$. \\
\hline $\mathrm{Me}$ & medial amygdaloid $\mathrm{n}$. \\
\hline MePV & medial amygrdaloid n., poster \\
\hline
\end{tabular}

\begin{tabular}{|c|c|}
\hline $\mathrm{mp}$ & medial parvicellular division, $\mathrm{PVN}$ \\
\hline MP & medial preoptic $n$. \\
\hline MPA & medial preoptic area \\
\hline MS & medial septal $n$. \\
\hline mt & mammillothalamic tract \\
\hline ot & optic tract \\
\hline $\mathrm{ox}$ & optic chiasm \\
\hline pi & posterior intermediate division, BST \\
\hline $\mathrm{pl}$ & posterior lateral division, BST \\
\hline $\mathrm{pm}$ & posterior medial division, BST \\
\hline po & preoptic division, BST \\
\hline PS & parastrial $n$. \\
\hline P'l' & paratenial thalamie $n$. \\
\hline PVA & thalamic paraventricular $n$. \\
\hline PVN & hypothalamic paraventricular $n$. \\
\hline $\mathrm{RCh}$ & retrochiasmatic n. \\
\hline $\operatorname{Re}$ & reuniens thalamic $n$. \\
\hline Rt & reticular thalamic $n$. \\
\hline $\mathrm{SCh}$ & suprachiasmatic n. \\
\hline SFi & septofimbrial $\mathbf{n}$. \\
\hline $\mathrm{SHy}$ & septohypothalamic $n$. \\
\hline SI & sublenticular substantia innominata \\
\hline $\mathrm{sm}$ & stria medullaris \\
\hline SO & supraoptic n. \\
\hline st & stria terminalis \\
\hline Sub & subiculum \\
\hline Tu & olfactory tubercle \\
\hline $\mathrm{vl}$ & ventral lateral division, BST \\
\hline VL & ventrolateral thalamic $n$. \\
\hline $\mathrm{vm}$ & ventral medial division, $\mathrm{BST}$ \\
\hline $\mathrm{VMH}$ & ventromedial hypothalamic $n$. \\
\hline VP & ventral pallidum \\
\hline VPL & ventral posterolateral thalamic $n$. \\
\hline ZI & zona incerta \\
\hline $3 \mathrm{~V}$ & third ventricle \\
\hline
\end{tabular}


with chloral hydrate $(300 \mathrm{mg} / \mathrm{kg})$, and mounted in a Kopf stereotaxic apparatus adjusted to coordinates according to the atlas of Paxinos and Watson ('86). Anterograde neuronal tract tracing was performed with PHA-L (Vector) according to the method of Gerfen and Sawchenko ('84). A $2.5 \%$ PHA-L solution diluted in $0.01 \mathrm{M}$ phosphate buffer $(\mathrm{pH}=8.0)$ was backfilled into glass micropipettes of tip diameter $15-20 \mu \mathrm{m}$. Iontophoretic injections to the ventral subiculum and surrounding regions were made $(5-6 \mu \mathrm{A} ; 7$ seconds on/off) for 15-20 minutes. For retrograde neuronal tracing, the tracer Fluoro-gold (Schmued and Fallon, '86) was employed. A $2 \%$ Fluoro-gold solution diluted in $0.9 \%$ $\mathrm{NaCl}$ was backfilled into glass micropipettes of tip diameter 10-15 $\mu \mathrm{m}$, and subsequently delivered to the PVN iontophoretically ( $3 \mu \mathrm{A} ; 7$ seconds on/off) for $1-3$ minutes. In all cases involving delivery of PHA-L or Fluoro-gold, the pipette was left in place following delivery for 15 minutes to minimize tracer diffusion along the pipette track. Five animals received Fluoro-gold injections alone; 15 animals received injections of PHA-L with Fluoro-gold delivered to the ipsilateral side. Survival periods ranged from 10 to 21 days. In an effort to discern the fiber pathways by which subicular efferents reach the BST, in five additional cases injections of PHA-L alone were made, with animals sacrificed at various periods ranging from 1 to 5 days.

Following survival periods, all animals were deeply anesthetized and perfused transcardially with $50 \mathrm{ml}$ saline, followed by $350 \mathrm{ml}$ of a fixative containing $4 \%$ paraformaldehyde in $0.1 \mathrm{M}$ sodium phosphate buffer $(\mathrm{pH}=7.4)(\mathrm{PB})$. Brains were removed and postfixed overnight in the same fixative to which $20 \%$ sucrose had been added, subsequently frozen on dry ice, and cut on a sliding microtome in the coronal plane into six series of $20 \mu \mathrm{m}$ sections. Sections were then placed in a cryoprotectant solution and stored at $-20^{\circ}$ until further processing.

\section{Immunocytochemistry}

Prior to all immunocytochemical steps, sections were routinely rinsed several times in ice cold $\mathrm{PB}$. Antisera were diluted in PB to which $0.5 \%$ Triton $\mathrm{X}-100$ and $0.25 \%$ carrageenan (Sigma, lambda type) had been added. All incubations were carried out under gentle agitation at $4^{\circ} \mathrm{C}$.

PHA-L was detected by the avidin-biotin-peroxidase (ABC) technique. Sections were incubated in a goat anti-PHA-L antiserum (Vector) at a dilution of 1:2,000 for 36 hours. This was succeeded by a biotinylated rabbit anti-sheep antiserum (Vector; 1:100) for 4 hours, and the ABC complex (Vector) at a dilution of 1:500 for 4 hours. This was followed by the coupled oxidation reaction (Itoh et al., '79) in a solution containing $50 \mathrm{mg} 3,3^{\prime}$-diaminobenzidene (DAB) tetrahydrochloride, $40 \mathrm{mg}$ ammonium chloride, 0.4 $\mathrm{mg}$ glucose oxidase (Sigma, type VII), and $200 \mathrm{mg} \mathrm{B-D-}$ glucose, per $100 \mathrm{ml} \mathrm{PB}$. Sections were then rinsed, mounted onto poly-lysine coated slides, dehydrated in a series of alcohols, placed in xylene for several hours, and coverslipped with DPX.

Immunocytochemical detection of Fluoro-gold was performed according to the peroxidase-antiperoxidase (PAP) method. Sections were incubated in an anti-Fluoro-gold antibody (Chang et al., '90) prepared in rabbit $(1: 4,000)$ for 36 hours, followed by a donkey anti-rabbit IgG (Chemicon) at 1:100 for 4 hours, and the rabbit PAP complex at 1:100 for 3 hours. This was succeeded by the coupled oxidation $\mathrm{DAB}$ reaction as described above.

In cases involving dual tracer injections, a doublelabeling protocol was employed for the simultaneous visual- ization of PHA-L and Fluoro-gold. PHA-L was detected in the first immunocytochemical sequence as described above, except that the secondary antibody was a biotinylated anti-goat IgG prepared in donkey (Chemicon), and the nickel-enhanced DAB color modification of Hsu and Soban ('82) was employed. Fluoro-gold was then detected in the second immunocytochemical sequence as previously described, except that the primary antiserum was used at a $1: 2,000$ dilution.

To control for the possibility of cross-reactivity between immunoreagents or secondary antisera in the doublelabeling studies, a series of sections was processed in the full immunocytochemical sequence with one or both primary antibodies deleted, or replaced with normal goat or rabbit serum. No evidence of labeling was encountered in these experiments.

\section{In situ hybridization histochemistry}

Three animals were sacrificed by rapid decapitation, and brains were removed, frozen in isopentane at $-40^{\circ} \mathrm{C}$, subsequently sectioned at $15 \mu \mathrm{m}$ using a cryostat (Hacker Instruments), mounted onto polylysine-coated slides, and fixed for 1 hour in $4 \%$ paraformaldehyde in PB. Tissue sections were deproteinated with proteinase $\mathrm{K}(0.1 \mu \mathrm{g} / \mathrm{ml})$ for 5 minutes at $37^{\circ} \mathrm{C}$. Slides were subsequently rinsed for several minutes in distilled $\mathrm{H}_{2} \mathrm{O}$, and then washed in $0.1 \mathrm{M}$ triethanolamine for 1 minute, and for 10 minutes following the addition of $0.25 \%$ acetic anhydride. Slides were then rinsed in distilled $\mathrm{H}_{2} \mathrm{O}$, and dehydrated in a progressive series of alcohols.

In situ hybridization for GAD mRNA was performed with a probe specific for the $\mathrm{M}_{\mathrm{r}} 67,000$ isoform of $\mathrm{GAD}\left(\mathrm{GAD}_{67}\right.$; courtesy of A. Tobin, UCLA). Plasmid containing $\mathrm{GAD}_{67}$ (HindII fragment subcloned in pGEM3) was linearized with $\mathrm{NcoI}$, and antisense ${ }^{35} \mathrm{~S}$-labeled cRNA probe $(210 \mathrm{nts})$ was synthesized using standard in vitro transcription methodology. The labeling reaction mixture contained the following: $1 \mu \mathrm{g}$ linearized plasmid, $1 \times$ SP6 transcription buffer (BRL), $125 \mu \mathrm{Ci}{ }^{35} \mathrm{~S}-\mathrm{UTP}, 150 \mu \mathrm{M}$ NTPs-UTP, $12.5 \mathrm{mM}$ dithiothreitol, $20 \mathrm{U}$ RNAsin, and $6 \mathrm{U} \mathrm{T} 7$ polymerase. The reaction was allowed to proceed for 90 minutes at $37^{\circ} \mathrm{C}$, and probe was separated from free nucleotides over a Sephadex G50-50 column. Probes were diluted in hybridization buffer to yield approximately $1,500,000 \mathrm{dpm} / 30 \mu \mathrm{l}$ buffer. The hybridization buffer consisted of $75 \%$ formamide, $10 \%$ dextran sulfate, $3 \mathrm{X}$ SSC, $50 \mathrm{mM}$ sodium phosphate buffer $(\mathrm{pH}=7.4), 1 \mathrm{X}$ Denhardt's solution, $0.1 \mathrm{mg} / \mathrm{ml}$ sheared salmon sperm DNA, and $0.1 \mathrm{mg} / \mathrm{ml}$ yeast tRNA. Diluted probe $(30 \mu \mathrm{l})$ was applied to each slide, with slides coverslipped and sealed at their borders with rubber cement. Slides were then placed in moistened chambers, and incubations were allowed to proceed for $12-30$ hours at $57^{\circ} \mathrm{C}$. Following hybridization, coverslips were removed in $1 \mathrm{X}$ SSC, and slides were subsequently washed several times in 1X SSC for 10 minutes. Slides were then treated with RNase A $(200 \mu \mathrm{g} / \mathrm{ml})$ for $30-60$ minutes at $37^{\circ} \mathrm{C}$, and washed successively in $1 \mathrm{X}, 0.5 \mathrm{X}$, and $0.2 \mathrm{X}$ SSC for 10 minutes each, followed by a 1.5 hour wash in $0.2 \mathrm{X}$ SSC at $60^{\circ} \mathrm{C}$. Slides were then dehydrated in alcohols, exposed to Kodak XAR X-ray film for 24-36 hours, and ultimately dipped in Kodak NTB2 emulsion. Emulsion-dipped slides were then stored in light-tight boxes for $10-21$ days at $4^{\circ} \mathrm{C}$. Slides were developed in Kodak D-19 developer, and subsequently dehydrated, placed in xylene for 20 minutes, and coverslipped with DPX. Control experiments were performed on tissue sections pretreated with RNase A. Evi- 
dence of labeling was not encountered in these experiments. The proportions of neurons expressing $\mathrm{GAD}_{67} \mathrm{mRNA}$ within BST subdivisions were determined visually from a minimum of three to five sections counterstained with cresyl violet. Counts of labeled/non-labeled neurons were registered with the aid of an ocular reticle placed over a given BST subnucleus corresponding to a $200 \times 200 \mu \mathrm{m}$ area of the section. Labeling of positive cells was typically at least 5 to 10 times that of background levels.

\section{Fluoro-gold immunocytochemistry combined with GAD in situ hybridization}

GAD in situ hybridization was performed on sections previously immunolabeled for Fluoro-gold. The Fluoro-gold immunolabeling was performed on floating sections as previously described, except that $20 \mathrm{nM}$ vanadyl ribonucleosidase (Sigma) was added to the incubation and rinse solutions to inhibit RNase activity. Sections were subsequently mounted onto coated slides, dehydrated in a progressive series of alcohols, and stored overnight. GAD in situ hybridization was then performed as described above, except that in some cases the proteinase $K$ step was omitted. Exposure times for emulsion-dipped sections varied between 10 and 14 days. Control in situ hybridization experiments were run on Fluoro-gold-immunolabeled seetions pretreated with RNase A $(200 \mu \mathrm{g} / \mathrm{ml})$ and did not show evidence of labeling.

\section{RESULTS Terminology}

Parcellations of the bed nucleus of the stria terminalis have traditionally emphasized medial and lateral divisions associated with neuroendocrine/reproductive and autonomic functions, respectively. Recently, several detailed descriptions of the BST have subdivided the nucleus on the basis of cytoarchitectural, chemoarchitectural, and connectional data, to which the reader is referred (de Olmos et al., '85; Ju and Swanson, '89; Ju et al., '89; Moga et al., '89). For the purposes of the present study, we have maintained many of the major BST divisions defined by Moga et al. ('89), as this study most closely resembled the present cytoarchitectural and connectional data. The parastrial nucleus, while considered to be distinct from the BST, has been included in the present description in view of its similarities to the BST in cytoarchitecture and peptide content (Moga et al., '89). The terminology outlined in the second edition of the atlas of Paxinos and Watson ('86) was adopted for the delineation of most other rostral forebrain structures.

\section{Anterograde tracing experiments}

Discrete iontophoretic PHA-L injections were made in various aspects of the ventral subiculum, as well as in portions of the amygdalohippocampal transition area. The locations of PHA-L injection sites from 10 primarily nonoverlapping experiments are represented in Figure 1, and a typical PHA-L injection site is illustrated in Figure 8B. A description of pathways and forebrain terminations of these cases follows.

Cases 21, 32, and 05. The PHA-L injections in these cases were made at several different rostrocaudal levels in the proximal or lateral-most portion of the ventral subiculum, in the region previously termed prosubiculum (Mei-

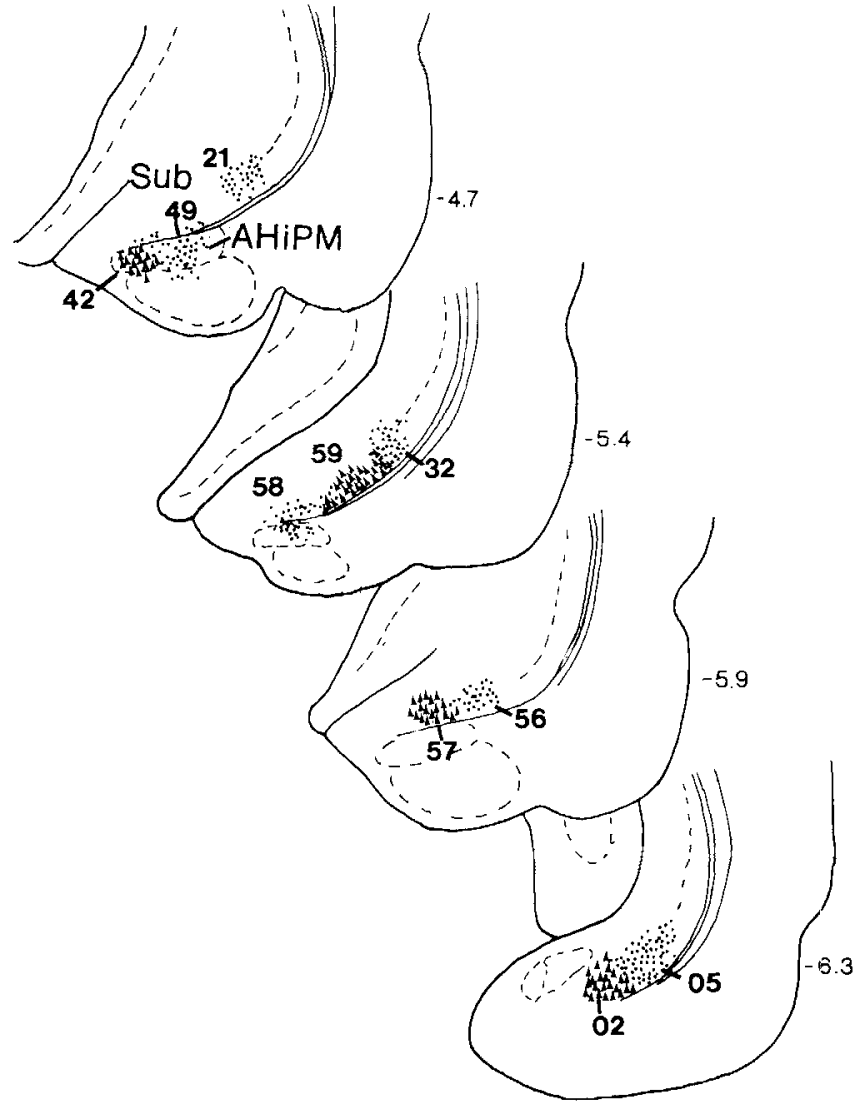

Fig. 1. Schematic diagram indicating the locations of Phaseolus vulgaris-leucoagglutinin (PHA-L) injection sites within the ventral subiculum or amygdalohippocampal transition area at levels approximately $4.7,5.4,5.9$, and $6.3 \mathrm{~mm}$ caudal to bregma.

bach and Siegel, '77). In cases 32 and 05 , a few neurons in the dentate gyrus were also labeled; however, in no cases could PHA-L-labeled cells be detected ventral to the subiculum in the entorhinal cortex or amygdalohippocampal transition area. The resulting patterns of forebrain labeling were similar among these cases, although the density of the innervation differed in the respective experiments, apparently as a function of the number of cells labeled at the injection sites. The labeling pattern from case 05 is shown at a series of forebrain levels in the darkfield micrographs of Figures 2 and 3 . In agreement with previous data (Köhler, '90; Witter and Groenewegen, '90), hippocampal efferents were seen to course from the injection site either: dorsally, through the alveus to the fimbria-fornix system, or ventrolaterally to the entorhinal cortex, and then anteriorly to the amygdala. These fiber systems are described in turn.

Fibers that coursed dorsally from the injection site ran through the lateral portion of the fimbria and could be detected in the precommisural and postcommisural portions of the fornix, as well as the medial corticohypothalamic tract. Precommissural fibers provided a massive input to the lateral septal nucleus, which was seen primarily within its intermediate subdivision (Fig. 2A,B). A similarly dense innervation was seen within the septofimbrial nucleus (Fig. 2B). Fibers bearing mainly en passant varicosities continued ventrally along the lateral border of the medial septal nucleus to the nuclei of the vertical and 

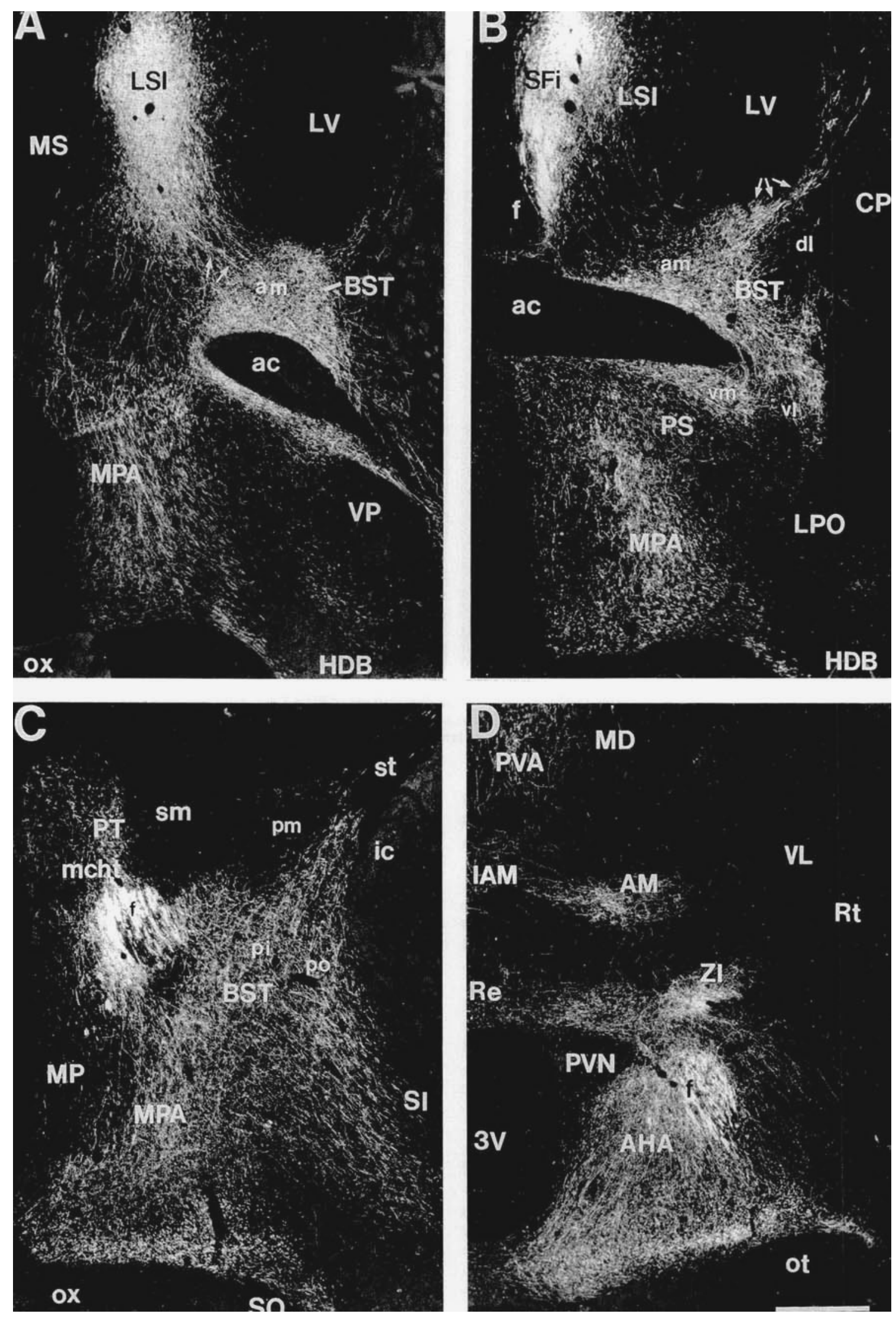

Fig. 2. Series of darkfield photomicrographs illustrating the distribution of PHA-L-labeled fibers and terminals at rostral (A), mid- (B), and caudal (C) BST levels, and at the level of the PVN (D), following a tracer injection in the lateral portion of the ventral subiculum (case 05). Arrows in A and B depict fibers that reach the BST via the fornix and stria terminalis, respectively. Scale bar $=0.5 \mathrm{~mm}$. 

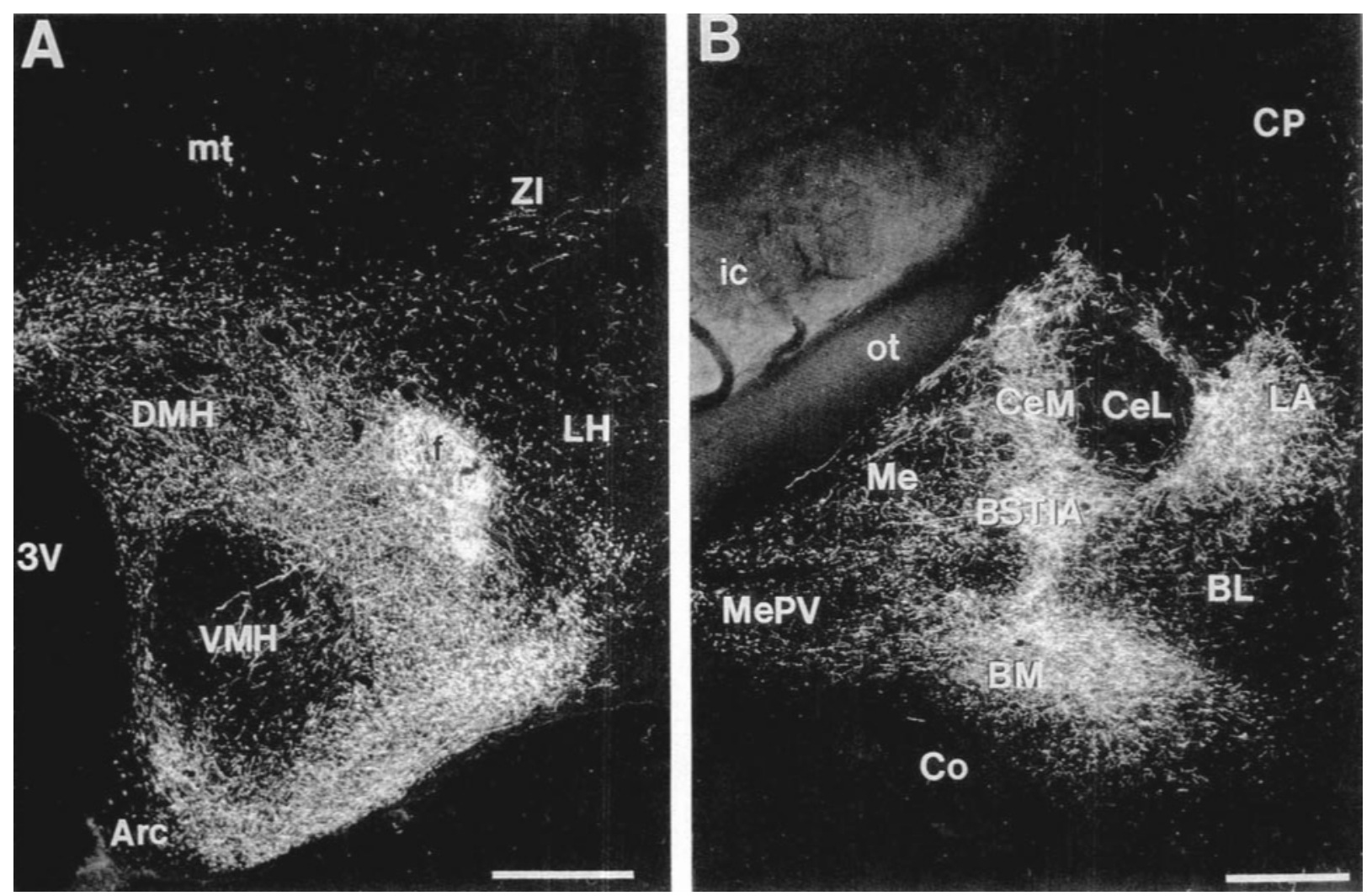

Fig. 3. Darkfield photomicrographs illustrating the distribution of PHA-L-labeled fibers and terminals at the level of the ventromedial hypothalamic nucleus $(\mathbf{A})$ and within the amygdala $(\mathbf{B})$, following a tracer injection in the lateral portion of the ventral subiculum (case 05). Scale bars $=0.5 \mathrm{~mm}$.

horizontal limbs of the diagonal band, where they appeared to turn caudally. Other precommissural fornix fibers turned ventrolaterally at the level of the septum, distributing a dense network of fibers and terminals to the BST (Fig. $2 \mathrm{~A}, \mathrm{~B})$. Some axons coursing in the postcommissural fornix and the proximal portion of the medial corticohypothalamic tract could be followed laterally to the caudal BST; a contingent of these postcommissural fornix fibers turned ventrolaterally, coursed through the sublenticular substantia innominata (SI) in the region corresponding to the ventral amygdalofugal pathway (Novotny, '77), and could be followed to the anterior amygdaloid area and medial amygdaloid nucleus. PHA-L-labeled axons that detached from the postcommissural fornix and medial corticohypothalamic tract also heavily innervated numerous hypothalamic regions, including the medial preoptic area (Fig. $2 \mathrm{C}$ ), anterior hypothalamic area, regions surrounding the paraventricular (Fig. 2D) and ventromedial hypothalamic nuclei (Fig. 3A), and mammillary region. Labeled fibers and terminals were also seen within the dorsomedial hypothalamic nucleus (Fig. 3A), and relatively light labeling was seen within the medial preoptic nucleus (Fig. 2C). Labeling was not detected within the PVN itself, other than for a few passing fibers, nor were labeled fibers evident within the supraoptic nucleus. Postcommissural fornix fibers also coursed within the subiculothalamic tract to the thalamus, where labeling was seen within the thalamic paraventricular, paratenial, and anteromedial nuclei, and to a lesser extent within the interanteromedial and reuniens nuclei
(Fig. 2C,D). Dense labeling was observed within the rostromedial tip of the zona incerta (Fig. 2D).

Fibers that coursed ventrolaterally from the injection site to the entorhinal cortex could be followed anteriorly to the amygdala, where dense fiber/terminal networks were seen within the lateral amygdaloid nucleus, medial amygdaloid nucleus, the basomedial nucleus, the medial part of the central nucleus, and the intraamygdalar division of the BS'T (BSTIA) (Fig. 3B). Labeling was relatively sparse in the basolateral nucleus. A prominent network of fibers/ terminals was seen to surround the lateral division of the central amygdaloid nucleus, although, like the paraventricular hypothalamic nucleus, this region was largely devoid of labeling (Fig. 3B). Some axons could be followed to the caudal portion of the caudate putamen, while other fibers continued to more rostral portions of the medial amygdaloid nucleus. Within the amygdala, a small contingent of fibers was consistently seen collected within the stria terminalis, mainly along its lateral border (Fig. 4B). These fibers could be followed along the course of the stria terminalis (Fig. 4A,B) to the BST (Fig. 2B,C), where dense terminal networks were elaborated.

At the level of the BST, some fibers arriving via the stria terminalis could be followed ventrally to the anterior hypothalamic area, where they merged with the terminal plexus originating from the fornix system (Fig. 2C). A separate contingent of the fibers from the stria terminalis coursed ventrally within the caudolateral $\mathrm{BST}$, continuing ventrolaterally through the SI, where they were joined by 

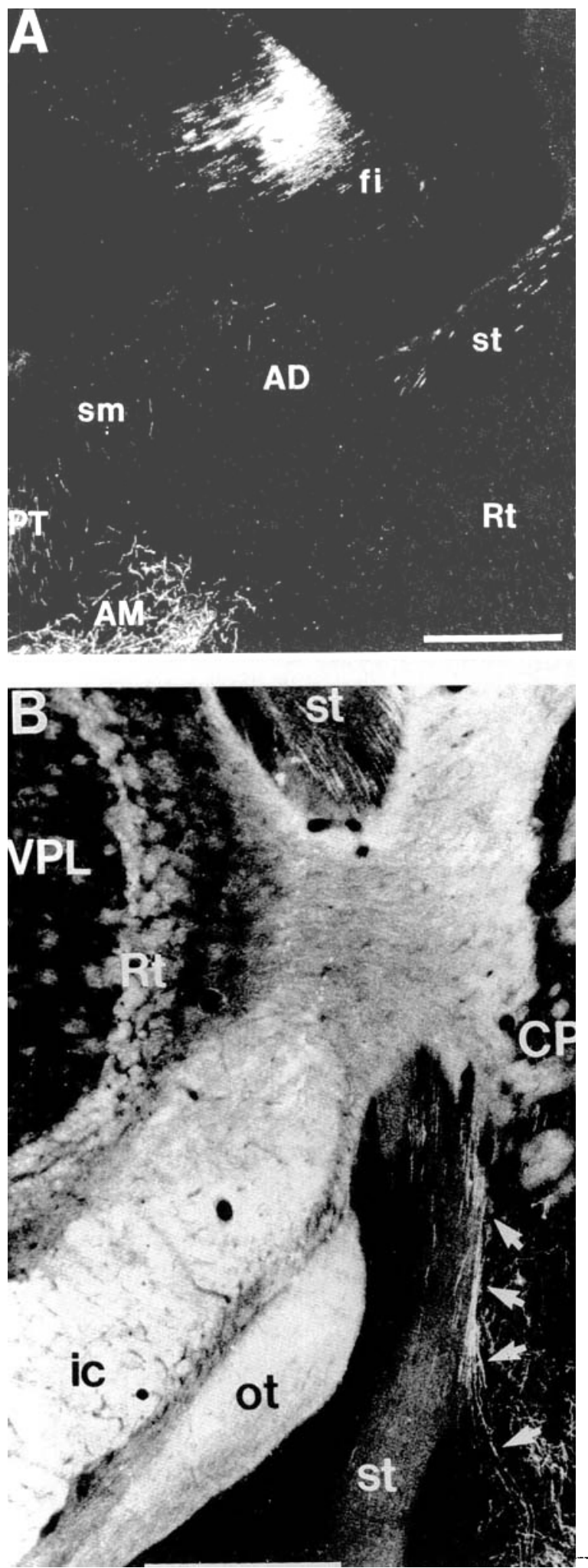

fibers from the postcommissural fornix and medial corticohypothalamic tract, before reaching the anterior and medial nuclei of the amygdala.
Fig. 4. A: Darkfield photomicrograph taken at a forebrain level approximately $1.2 \mathrm{~mm}$ caudal to bregma, illustrating labeled fibers within the lateral portion of the fimbria-fornix and within the stria terminalis following a PHA-L injection in the lateral portion of the ventral subiculum. B: Darkfield photomicrograph taken at a forebrain level approximately $3.5 \mathrm{~mm}$ caudal to bregma, illustrating PHA-Llabeled fibers (arrows) within the amygdaloid portion of the stria terminalis following a tracer injection in the lateral part of the ventral subiculum. Scale bars $=0.5 \mathrm{~mm}$.

It should also be noted that in all of these cases, labeled axons resembling fibers of passage were seen within the ventral portion of the striatum beneath the posterior limb of the anterior commissure. These fibers were continuous rostrally with the nucleus accumbens and rostral BST, and caudally with the amygdala; however, their direction could not be determined.

Within the BST, dense networks of PHA-L fibers and terminals were concentrated in the anterior medial, anterior lateral, ventral medial, posterior intermediate, and preoptic divisions of this structure (Fig. 2A-C). Fewer fibers/terminals were detected in the ventral lateral BST subdivision, and light labeling was seen in the parastrial nucleus. The dorsal lateral and posterior lateral divisions of the BST were largely avoided (Fig. 2B), as was the posterior medial division (Fig. 2C).

Cases 56, 57, and 59. In these cases the PHA-L injections were located centrally within the ventral subiculum, with case 56 labeling cells immediately lateral to those in case 57 (Fig. 1). The PHA-L injection site in case 59 was centered in the same mediolateral location as that in case 57 , approximately $0.5 \mathrm{~mm}$ anteriorly. The pathways by which labeled axons coursed to the forebrain, as well as the forebrain distribution patterns of fiber/terminal labeling from the three cases, were similar to those following injections placed more laterally in the ventral subiculum, with several notable exceptions:

1. Labeling within the stria terminalis was somewhat lighter than from cases involving tracer injections in the lateral portion of the ventral subiculum; however, some fibers could be followed to the BST through the adjacent portions of the caudate putamen.

2. The labeling pattern of fibers/terminals differed within the caudal portion of the BST, where it was largely restricted to the posterior intermediate division (Fig. 5C), with few fibers detected within the preoptic division.

3. Labeling within the medial corticohypothalamic tract (Fig. 5C) was far more prominent than in cases involving the lateral portion of the ventral subiculum (Fig. 2C). Consequently, labeling within some medial hypothalamic groups was heavier in these cases. This was particularly apparent within parts of the anterior hypothalamic area and several caudomedial hypothalamic regions. Similar to more laterally placed injections, however, many portions of the medial hypothalamus received innervation from fibers that detached from both the medial corticohypothalamic tract and the fornix.

4. Labeling within the anteromedial thalamic nucleus and rostromedial zona incerta was light or absent (Fig. 5D).

Additional cases. The PHA-L injection site in case 02 (Fig. 1) was located within the caudomedial aspect of the ventral subiculum, immediately adjacent to case 05 . Interestingly, the forebrain labeling pattern was distinct from that in case 05 , in that relatively sparse labeling was detected in the most hypothalamic areas and only a few scattered fibers were observed in the BST, although several 

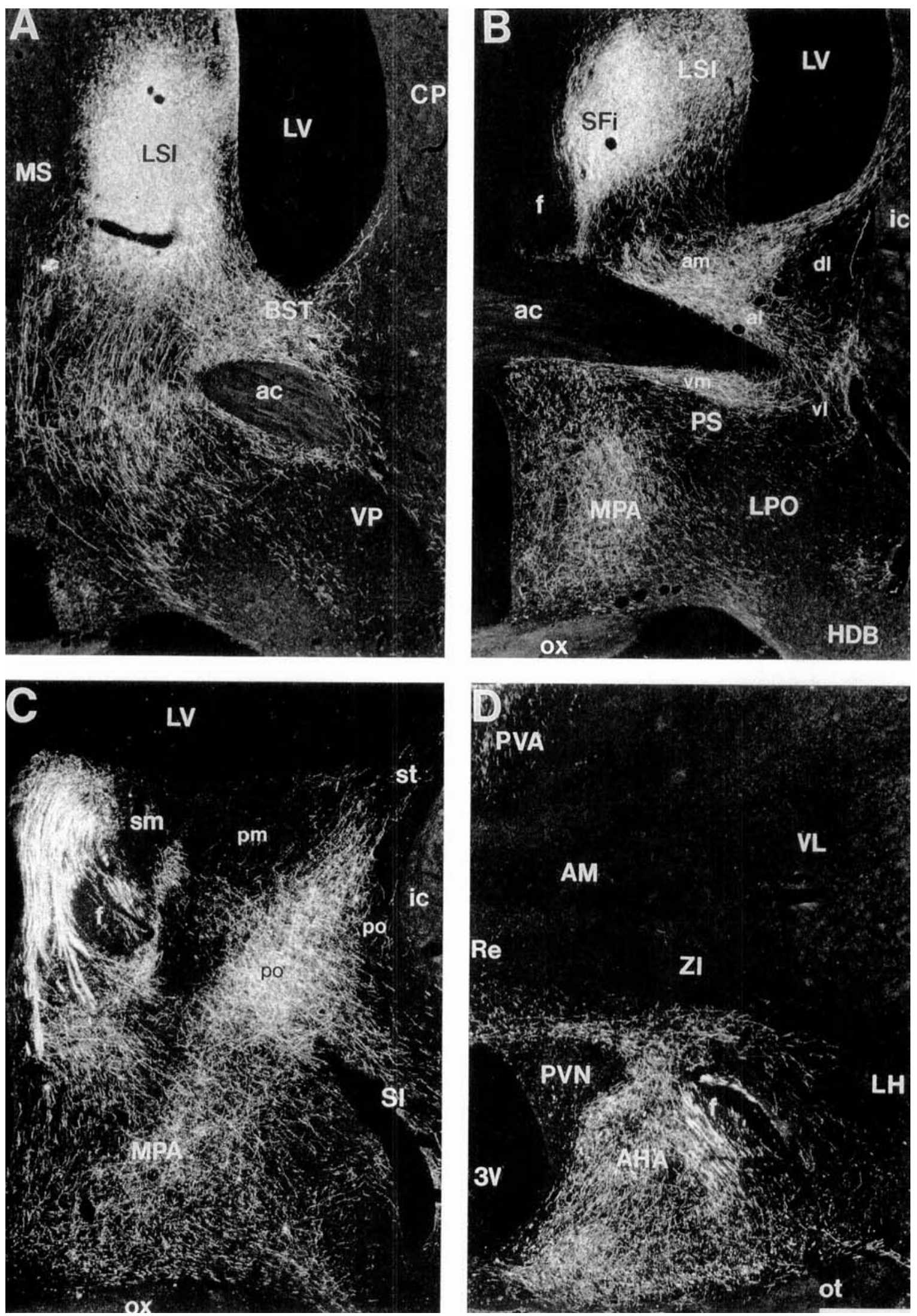

Fig. 5. Series of darkfield photomicrographs illustrating the distribution of PHA-L-labeled fibers and terminals at rostral (A), mid- (B), and caudal (C) levels of the BST, as well as the level of the PVN (D following a tracer injection within a mid-portion of the ventral subiculum (case 57 ). Scale bar $=0.5 \mathrm{~mm}$. 


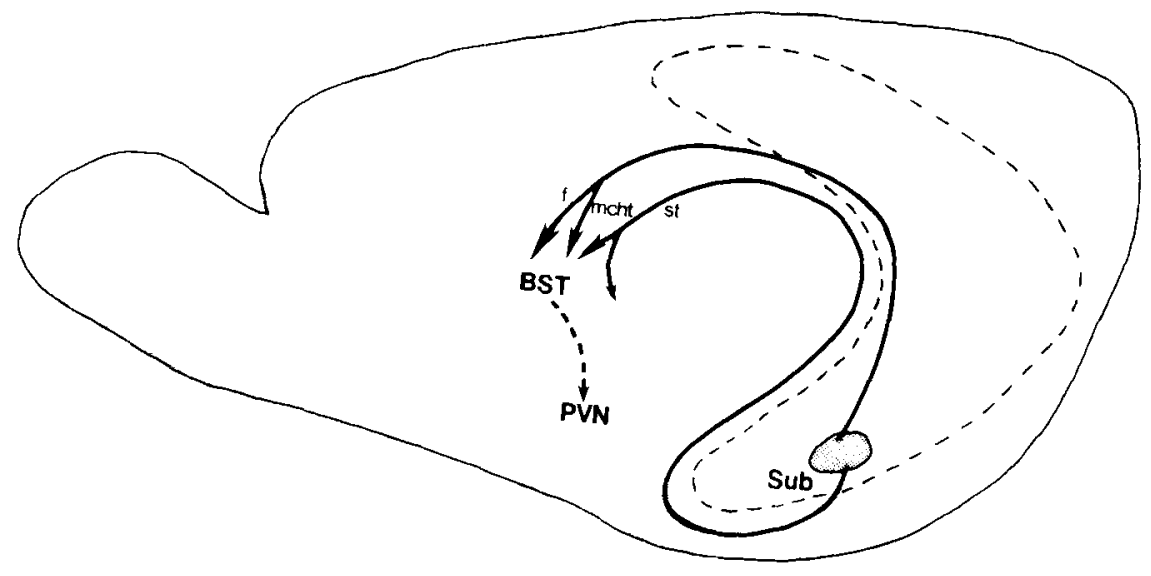

Fig. 6. Schematic diagram illustrating fiber pathways mediating ventral subicular projections to the BST.

thalamic nuclei were prominently labeled (reuniens, anteroventral). No evidence of labeling in the stria terminalis was seen in this case.

The PHA-L injection in case 42 labeled neurons located rostromedially within the posteromedial division of the amygdalohippocampal transition area (AHiPM). Fibers emanating from the injection site coursed anteriorly through the amygdala, where a dense plexus of fibers and terminals was noted within the BSTIA, and to a lesser extent, within the medial part of the central nucleus. Labeled axons could be followed through the stria terminalis to the BST, where fiber/terminal networks were seen. No labeled axons were detected within the fimbria-fornix from this case; thus, there was no evidence of labeling within forebrain regions innervated from this pathway. The PHA-L injection site in case 49 involved the mid-portion AHiPM, as well as few cells in the overlying ventral subiculum. Consequently, fiber labeling was prominent in the stria terminalis, but was light within the fimbria-fornix. Labeled fibers and terminals were most abundant within medial portions of the BST, but were present in all subnuclei with the exception of the posterior medial subdivision, which was avoided. In general, however, labeling within the BST following PHA-L injections involving in the AHiPM was less dense than that seen following subicular injections. The injection site in case 58 (Fig. 1) involved the ventral subiculum and underlying AHiPM equally. The mixed nature of the injection site in this case was evident in that labeled fibers were equally prominent in the fimbria-fornix and stria terminalis. Within the BST, all regions received input except the posterior medial subdivision, although this innervation was densest in the anterior medial, ventral medial, anterior lateral, and posterior intermediate subdivisions. The labeling pattern throughout other portions of the forebrain mirrored that of case 57 . The innervation patterns within the BST from these cases suggest that lateral parts of the BST avoided by projections from the ventral subiculum receive some input from mid-portions of the AHiPM, and that AHiPM projections reach the BST through the stria terminalis.

Time course studies. To examine the trajectories of labeled fibers within the stria terminalis following PHA-L injections in the ventral subiculum, animals were sacrificed at various time points after tracer injections confined to the lateral portion of the ventral subiculum (similar to case 05).
At 24 hours post-injection (case 46), although no labeling was detected within the BST or hypothalamus, a network of labeled fibers and terminals was seen within the amygdala, and labeled axons were seen collected within the amygdaloid portion of the stria terminalis; no labeled fibers were detected in the more anterior portions of this tract, however, indicating that transport of the lectin had not yet reached the BST. Labeled axons from this case were also prominent laterally within the fimbria, but PHA-L transport was arrested at a mid-portion of this structure; there was no evidence of labeled axons within the fimbria beyond a point approximately $2.3 \mathrm{~mm}$ caudal to bregma. At 48 hours post-injection (case 45), labeled fibers were detected throughout the stria terminalis and the BST, as well as within the fornix as far as mid-hypothalamic levels, although none were seen caudal to the level of the dorsomedial hypothalamic nucleus (approx. $2.8 \mathrm{~mm}$ caudal to bregma). At 72 hours post-injection (case 44), the pattern of labeling in the basal forebrain was identical to case 05 , suggesting that transport of the lectin was essentially complete. These findings are consistent with the approximated rate of PHA-L transport (4-6 mm/day) reported by Gerfen and Sawchenko ('84). The results suggest that following PHA-L injections in the ventral subiculum, at least a proportion, and possibly all, of the labeled axons detected in the stria terminalis course toward the BST, and not in the opposite direction, i.e., en route to the amygdala after detaching from the fornix at the level of the BST. The findings therefore suggest that subicular efferents to the BST arrive via at least two distinct pathways: 1) the fornix, including a small contingent of fibers that detached from the early (most proximal) medial corticohypothalamic tract; and 2) the stria terminalis, including some axons that follow its course in the adjacent parts of the caudate putamen. These relationships are summarized in the diagram of Figure 6.

\section{Retrograde tracing experiments}

Discrete iontophoretic injections of the retrograde neuronal tracer Fluoro-gold were aimed at the PVN; the injection sites were confined mainly within the nucleus in five cases, four of which are depicted in the composite diagram of Figure 7. In case 35 the Fluoro-gold injection was located primarily within the dorsal parvicellular and medial parvi- 


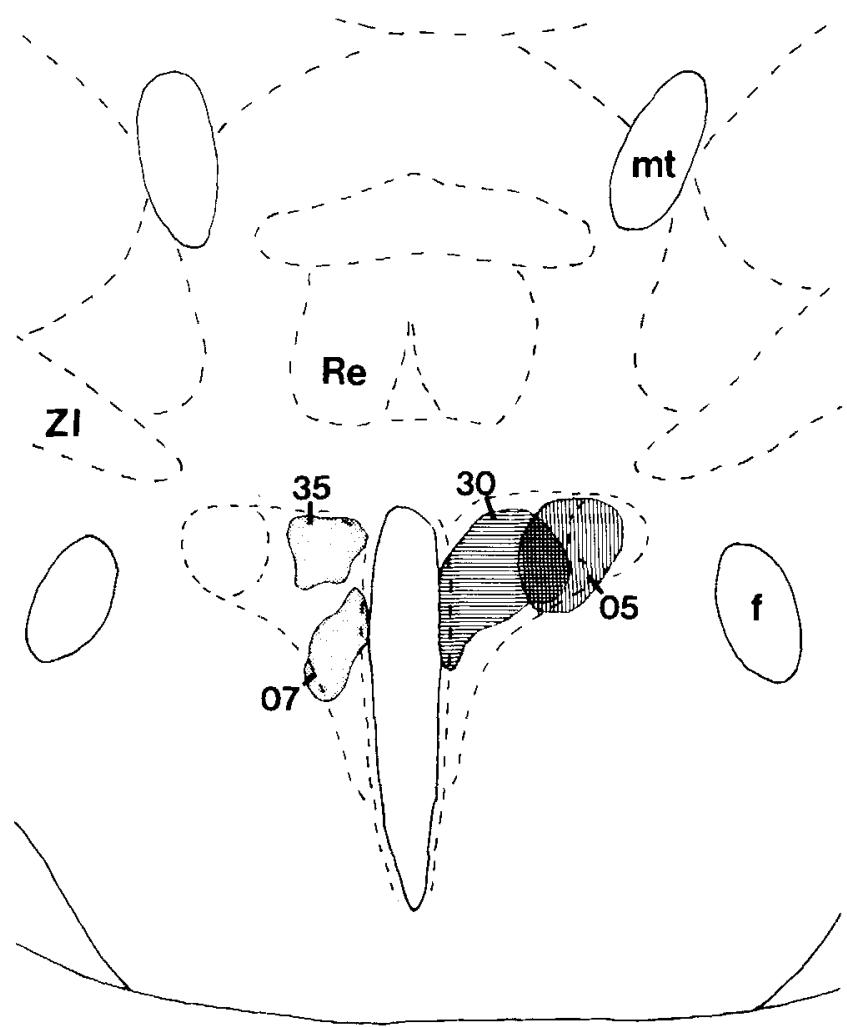

Fig. 7. Summary diagram of Fluoro-gold injections directed at the PVN, adapted from the atlas of Paxinos and Watson ('86).

cellular divisions of the PVN, whereas in case 07 the injection site was apparently confined mainly to the ventral portion of the medial parvicellular PVN. The tracer injections in cases 30 and 05 both involved much of the medial parvicellular PVN, although the injection site in case 05 also clearly extended to the posterior magnocellular PVN.

The injection parameters used in this study were minimized in an effort to limit the extent of diffusion of the tracer to the PVN. Consequently, only weak fluorescence was detectable within retrogradely labeled neurons in most forebrain regions. To facilitate detection of retrogradely labeled cells, immunocytochemistry was performed using a recently developed Fluoro-gold antisera that has been previously characterized (Chang et al., '90). Fluoro-goldlabeled neurons were found to be differentially distributed across subdivisions of the BST. The majority of labeled cells were found within the anterior medial, ventral medial, ventral lateral, and posterior intermediate subdivisions of the BST, as well as in the parastrial nucleus (Fig. 8). Fewer labeled cells were seen within the posterior medial and preoptic divisions, and very few or none could be detected in the lateral portions of the BST (i.e., dorsal lateral, posterior lateral divisions). The distribution patterns of retrogradely labeled neurons within the BST were similar among the cases, with the exceptions that in case 05 somewhat more cells were detected dorsally within the caudal portions of the BST, particularly in the posterior intermediate division, and in case 07 fewer total retrogradely labeled cells were seen. In other rostral forebrain regions the patterns of retrograde labeling were generally consistent with previously published data (Sawchenko and Swanson, '83a); however, some differences were noted. For example, few retrogradely labeled neurons were detected in the dorsal part of the lateral septal nucleus, and in most cases, relatively few labeled cells were seen in the rostromedial part of the zona incerta.

\section{Combined anterograde-retrograde tracing experiments}

In 15 animals receiving PHA-L injections in the ventral subiculum, Fluoro-gold was delivered to the ipsilateral PVN. In two of these cases analysis of the injection sites indicated that both tracers were appropriately placed within target areas, and a series of sections was processed for detection of PHA-L and Fluoro-gold using the NiDAB/DAB immunocytochemical double-labeling method. Within the BST, PHA-L-labeled terminal boutons were seen at high magnification $(100 x)$ in direct apposition to Fluoro-goldlabeled neuronal cell bodies or proximal dendritic segments (Figs. 8, 9D-F). These associations were common in the anterior medial, ventral medial, and posterior intermediate divisions of the BST, regions most heavily innervated by the ventral subiculum and in which the majority of retrogradely labeled cells were seen. PHA-L-labeled terminals abutting Fluoro-gold labeled cells were also observed, although infrequently, within the ventral lateral and preoptic divisions of the BST, and in the parastrial nucleus. In some cases Fluoro-gold-labeled neurons were seen surrounded by labeled terminals in "pericellular basket" arrangements highly suggestive of synaptic input, although typically cells were directly approximated by two to four labeled terminals. Close appositions between PHA-L-labeled fibers and Fluoro-gold-labeled cells were noted in a number of other rostral forebrain regions, including the anterior hypothalamic area, particularly in the region immediately ventral to the PVN, as well as the dorsomedial hypothalamic nucleus.

\section{GAD $_{67}$ mRNA expression in the BST}

Forebrain sections were processed using in situ hybridiza . tion histochemistry for detection of mRNA transcripts encoding GAD, using a cRNA probe specific for the $\mathrm{GAD}_{6}$ ? isoform (courtesy Dr. A. Tobin, UCLA). The forebrain distribution pattern of cells expressing $\mathrm{GAD}_{67} \mathrm{mRNA}$ was consistent with several recent reports (Ferraguti et al., '91; Erlander et al., '91), and is shown in the darkfield photomi. crographs of Figure 10 at rostral, mid-, and caudal levels of the BST, as well as at the level of the PVN. Counts from Nissl counterstained sections revealed that a consistently high proportion of $\mathrm{BST}$ neurons expressed $\mathrm{GAD}_{67}$ message, ranging from $75 \%$ in the ventral lateral division, to as high as $91 \%$ in the posterior medial division (Table 1). These findings are consistent with the immunocytochemical data of Mugnani and Oertel, ('85). The levels of expression of transcripts encoding $\mathrm{GAD}_{67}$ within individual BST neurons were generally much lower compared with those observed in cells within other forebrain areas, such as in the medial

Fig. 8. Camera lucida drawings on the left side show the distribution of neurons retrogradely labeled with Fluoro-gold at rostral (A) mid- (B), and caudal (C) levels of the BST in case 05. The camera lucid: drawings were made from PHA-L/Fluoro-gold double-labeled sections. Fluoro-gold-labeled neurons outside of the BST were omitted for simplicity. The boxed regions in the left drawings are shown in the corresponding drawings on the right, which illustrate the relationship between PHA-L-iabeled fibers and terminals and Fluoro-gold-immunolabeled neurons. Scale bars $:=50 \mu \mathrm{m}$. 


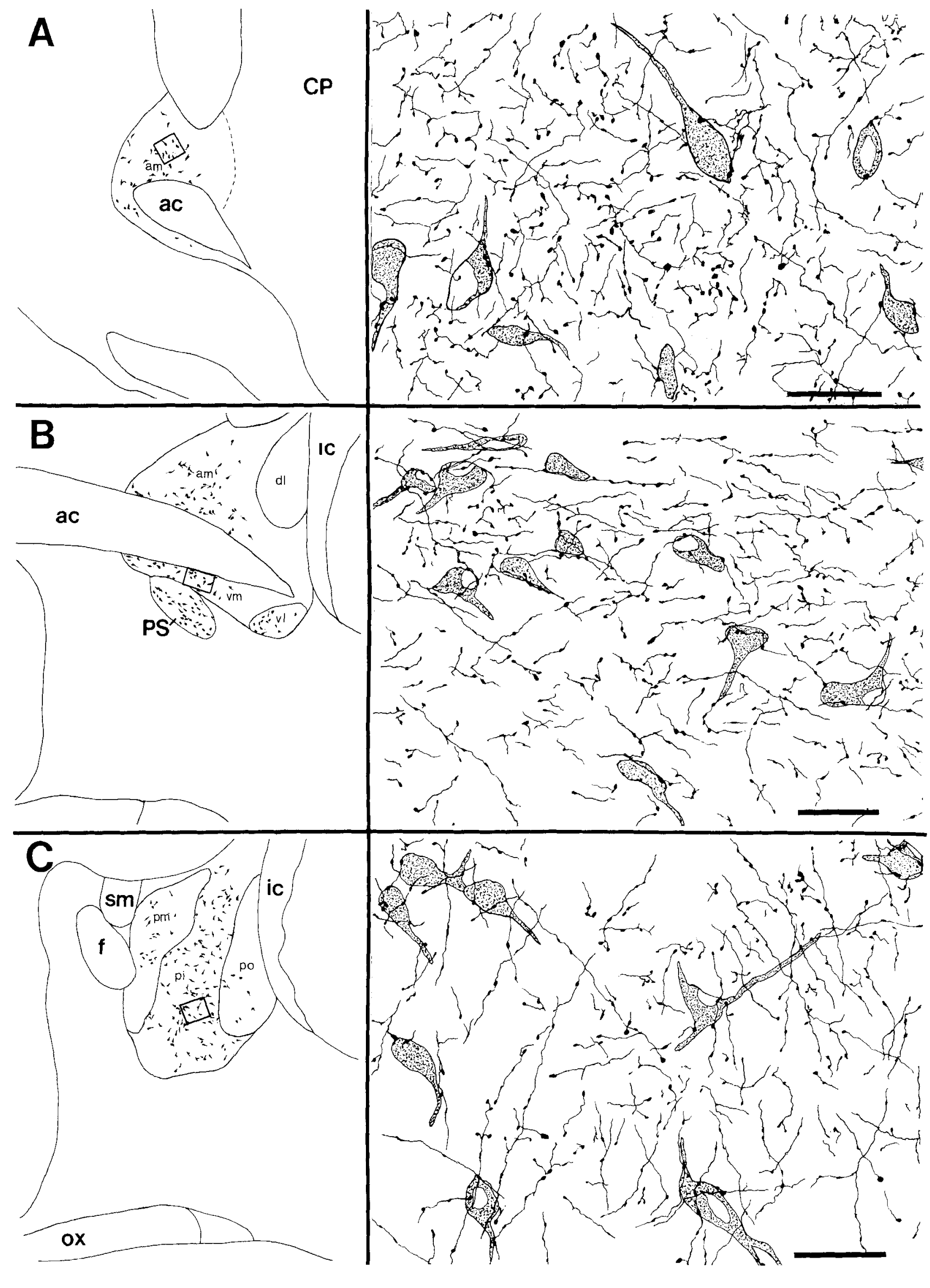

Figure 8 

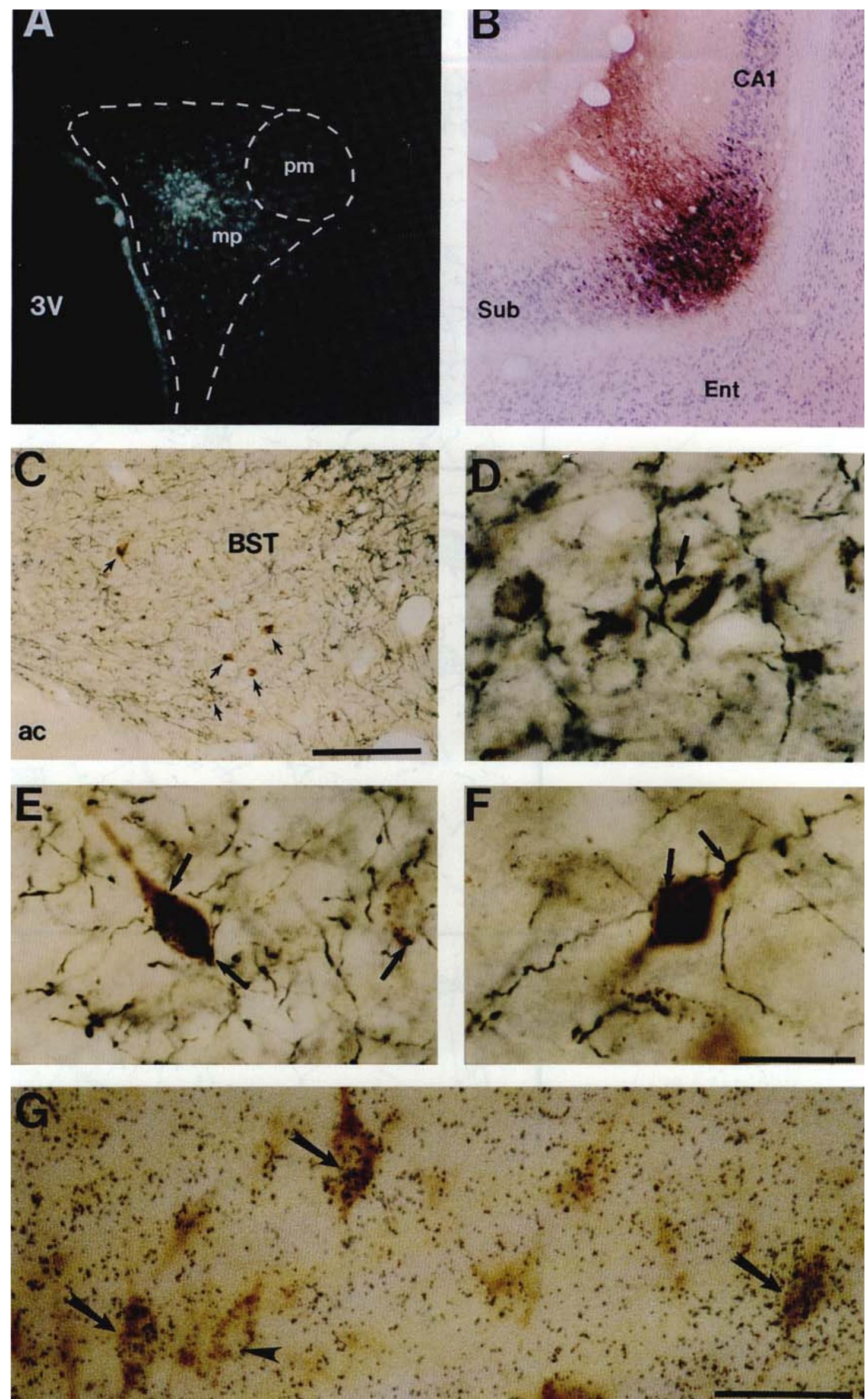
septal nucleus, diagonal band nuclei, caudate putamen, globus pallidus, and reticular thalamic nucleus. An exception to this was in the posterior medial subnucleus of the BST, where high levels of expression were noted. Also, a small number of scattered neurons within other BST subdivisions expressed high levels (arrow in Fig. 11A), and were most frequently encountered in the anterior medial and ventral medial BST subdivisions. Within the parastrial nucleus, approximately $71 \%$ of neurons were found to express $\mathrm{GAD}_{67} \mathrm{mRNA}$ transcripts, and the levels of expression within these neurons were similar (i.e., relatively low) to most portions of the BST.

\section{Combined Fluoro-gold immunocytochemistry/ GAD in situ hybridization}

Forebrain sections containing the BST from cases 30 and 35 were processed for Fluoro-gold immunocytochemistry in combination with detection of $\mathrm{GAD}_{67} \mathrm{mRNA}$ by in situ hybridization. Examples of cells labeled for Fluoro-gold/ GAD mRNA within the ventral medial and ventral lateral subdivisions of the BST are shown in Figures 9G and 12B, respectively. Although no systematic quantitative analysis was attempted due to technical limitations of this method (see Discussion), examination of series of emulsion-dipped sections from these cases revealed that expression of $\mathrm{GAD}_{67}$ mRNA could be detected in slightly more than half of the Fluoro-gold-labeled cells within the anterior medial, ventral medial, ventral lateral, and posterior intermediate divisions of the BST. These proportions were consistent across BST subdivisions examined in both cases. Other BST subregions were not evaluated due to the paucity of retrogradely labeled cells found. Expression of $\mathrm{GAD}_{67}$ transcripts could be detected in approximately $40 \%$ of the Fluoro-goldlabeled neurons in the parastrial nucleus. The data indicate that the PVN receives a portion of its GABAergic input from neurons located within the BST and parastrial nucleus.

\section{DISCUSSION}

A number of recent studies using the PHA-L tracing method have examined the projections from the ventral subiculum, underscoring the complexity of the forebrain projections of this region (Groenewegen et al., '87; Köhler, '90; Witter and Groenewegen, '90). The present results extend previous data concerning the ventral subicular projections to the BST, revealing a subregion-specifie pattern of innervation, and confirm previous suggestions (Krettek and Price, '78) that the stria terminalis is involved

Fig. 9. A: Fluoro-gold injection site centered in the medial parvicellular PVN in case 30 . The PVN borders were drawn from an adjacent counterstained section. B: PHA-L injection site located in the lateralmost portion of the ventral subiculum, adjacent to CAl (case 05), is shown from a section that has been Nissl counterstained. C: Low magnification view of PHA-L-labeled fibers and terminals in relation to Fluoro-gold-immunolabeled cells within the BST following a PHA-L injection in the ventral subiculum, and Fluoro-gold delivery to the PVN (case 05). D-F: High magnification illustrations of PHA-L-labeled terminals abutting Fluoro-gold-labeled elements (arrows) within the ventral medial $(D)$, anterior medial $(E)$, and posterior intermediate $(F)$ divisions of the BST from case 05. G: Fluoro-gold-immunolabeled neurons (case 30 ) in the ventral medial division of the BST from a section that was processed for $\mathrm{GAD}_{67}$ in situ hybridization. Doublelabeled cells are depicted by arrows. Arrowhead denotes cell labeled for $\mathrm{GAD}_{67}$ only. Scale bars: $\mathrm{C}=0.25 \mathrm{~mm}, \mathrm{~F}$ (for $\mathrm{D}-\mathrm{F}$ ) and $\mathrm{G}=50 \mu \mathrm{m}$. in this projection. Moreover, these experiments provide light microscopic evidence to suggest that the BST may mediate hippocampal influences on the PVN, and that such interactions are likely to occur predominantly within specific BST subregions. Finally, the present study provides a partial characterization of the chemical nature of the BST projection to the PVN, in that a proportion of this projection utilizes GABA as a neurotransmitter. These findings are likely to have important implications for studies exploring the regulation of the HPA axis. Before discussing these results, however, several technical aspects of the present study will be considered.

\section{Technical considerations}

The major advantages of the PHA-L and Fluoro-gold neuronal tracing methods have now been firmly established (Gerfen et al., '89; Schmued, '90) and will not be considered in detail; however, several technical aspects of the present experiments merit attention.

1. An important consideration in these studies concerns the localization of the tracer injection sites. While a principal advantage of the PHA-L method is the ability to define precisely the cells of origin of a given projection, analysis of the terminal regions incorporating retrograde tracers is considerably more difficult. This limitation is of particular concern when the target area of the retrograde injection is notably small, as in the case of the PVN. That the Fluorogold injections were confined primarily to the PVN itself is suggested by the fact that very few retrogradely labeled neurons were detected in the present cases within the ventral subiculum, which has been shown to innervate the region surrounding the $\mathrm{PVN}$, but to contribute few fibers to the nucleus itself (Swanson and Cowan, '77; Meibach and Siegel, '77; Köhler, '90; Witter and Groenewegen, '90; present study). Indeed, in cases in which Fluoro-gold injections were centered in proximity, but clearly outside the borders of the PVN, numerous retrogradely labeled neurons were detected within the ventral subiculum. Nevertheless, it remains possible that some of the present retrograde labeling could have resulted from tracer uptake that occurred at the periphery of the nucleus. It is important to note, however, that anterograde tracing studies utilizing the PHA-L method have confirmed projections to the mpPVN from the same major BST subdivisions (anterior medial, ventral medial, posterior intermediate, as well as the parastrial nucleus) that were retrogradely labeled following Fluoro-gold injection in the present study (Grove, ' 88 ; Simerly and Swanson, '88; Cullinan, Herman and Watson, unpublished data).

2. The recently developed antisera to Fluoro-gold adds a new dimension in terms of sensitivity to retrograde tracing studies using this compound (Chang et al., '90), including enhanced morphological detail, and often extensive visualization of dendrites. This advantage in sensitivity was of critical importance in the present experiments, since the injection parameters for Fluoro-gold delivery were greatly minimized in an effort to contain the tracer to the PVN, which results in a significantly diminished fluorescence signal in retrogradely labeled cells. It is also worth noting that even when relatively large Fluoro-gold injections were delivered to the PVN region, retrogradely labeled neurons in the BST were among the dimmest observable in the forebrain. Following application of the Fluoro-gold immunolabeling protocol in the present experiment, many more neurons were seen in the BST than could be observed in an 

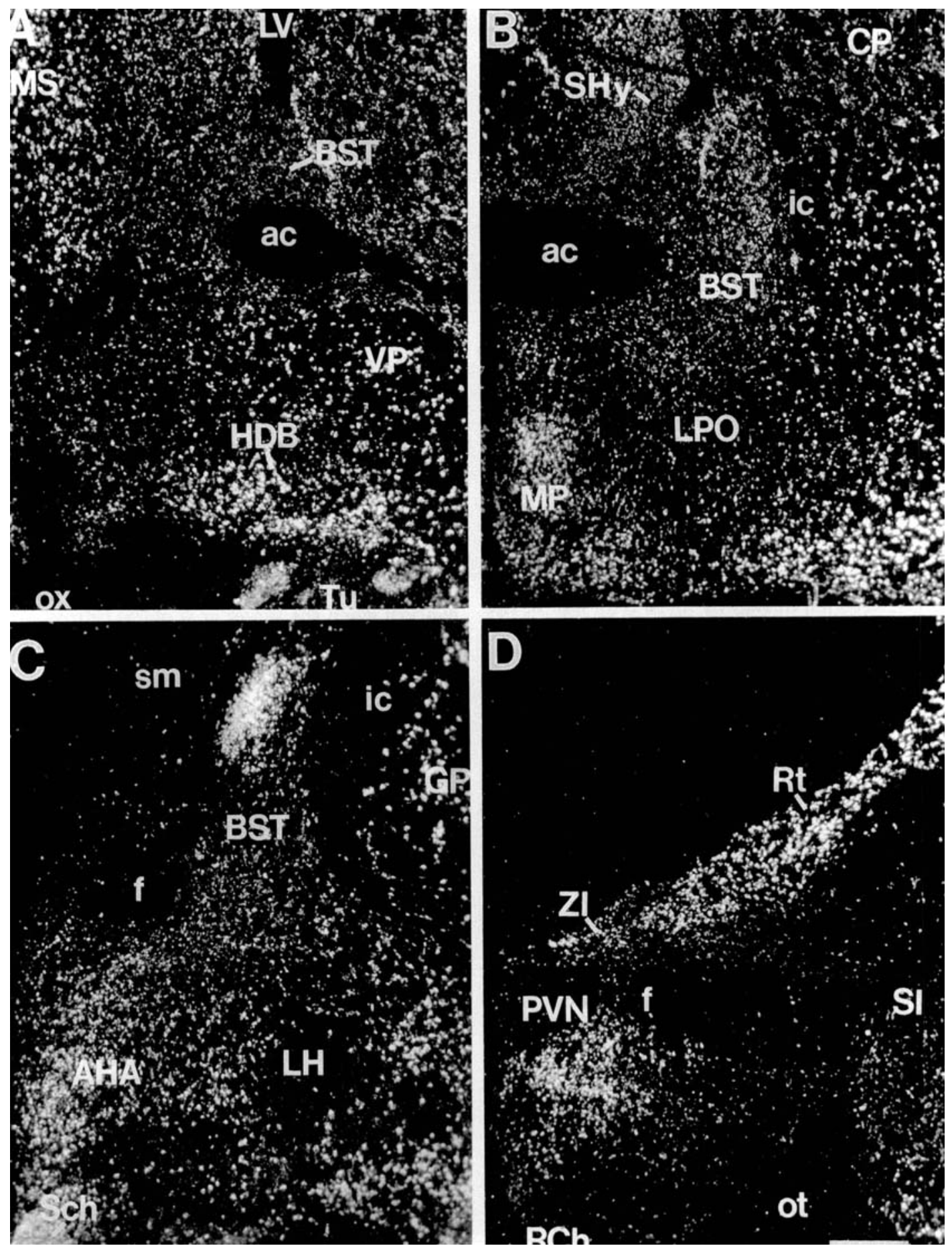

Fig. 10. Series of darkfield photomicrographs from emulsion-dipped sections at rostral (A), mid- (B), and caudal (C) levels of the BST, as well as the level of the PVN (D), following in situ hybridization with a probe for $\mathrm{GAD}_{67} \mathrm{mRNA}$. Scale bar $=0.5 \mathrm{~mm}$.

adjacent series of non-immunolabeled sections. However, despite this increase in sensitivity, dendritic labeling remained very limited, even when survival times exceeded 14 days. In view of Golgi evidence indicating that many BST neurons have dendrites that extend for distances of 300$400 \mu \mathrm{m}$ (McDonald, '83), it is likely that in the present dual tracing experiments, many putative contacts between PHAL-labeled terminals and Fluoro-gold-labeled elements would have been missed.

3. Application of the Fluoro-gold immunolabeling method also presents an important advantage for experiments in which detection of the tracer is combined with in situ 
TABLE 1. $\mathrm{GAD}_{67}$ mRNA Expression in the $\mathrm{BST}^{1}$

\begin{tabular}{lcc}
\hline Subdivision & No./'Total & $\%$ \\
\hline $\mathrm{am}$ & $477 / 584$ & 81.7 \\
$\mathrm{al}$ & $450 / 576$ & 78.1 \\
$\mathrm{vm}$ & $352 / 460$ & 76.5 \\
$\mathrm{vl}$ & $204 / 272$ & 75.0 \\
$\mathrm{dl}$ & $372 / 457$ & 81.4 \\
$\mathrm{pl}$ & $264 / 341$ & 77.4 \\
$\mathrm{pm}$ & $442 / 486$ & 90.9 \\
$\mathrm{pi}$ & $433 / 561$ & 77.2 \\
po & $260 / 352$ & 73.9 \\
PS & $160 / 223$ & 71.7 \\
\hline 'Cell counts of neurons within BST subdivisions that express $\mathrm{GAD}_{67}$ mRNA, derived from
\end{tabular}

sections within given subruclei taken from normal male Sprague-Dawley rats.
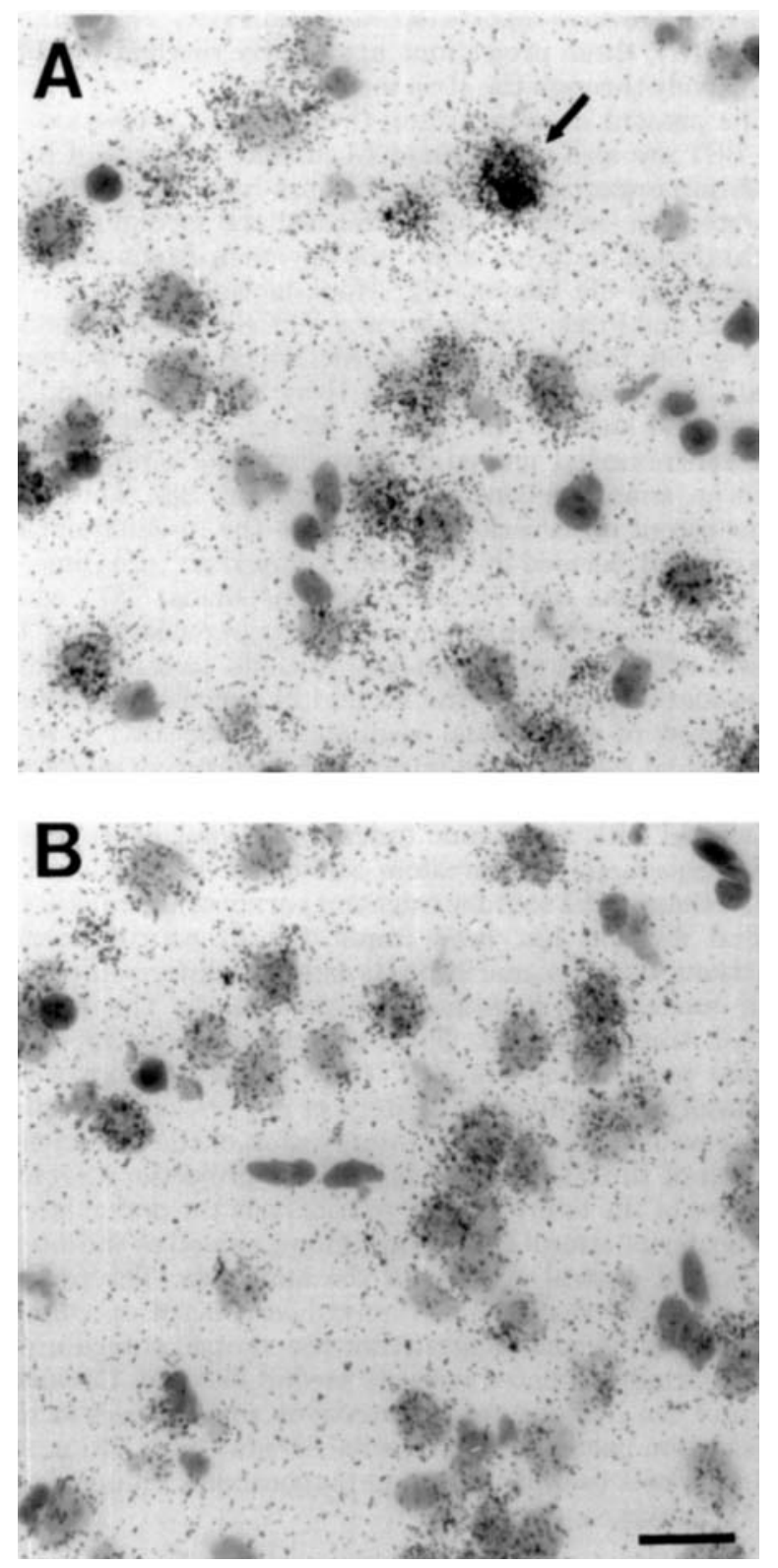

Fig. 11. High magnification photomicrographs illustrating the expression of $\mathrm{GAD}_{67}$ mRNA within neurons in the anterior medial (A) and ventral medial (B) divisions of the BST. Arrow in A denotes neuron expressing relatively high levels of $\mathrm{GAD}_{67}$ message. Scale bar $=25 \mu \mathrm{m}$. hybridization histochemistry. The high temperature washes involved in the use of cRNA probes are known to cause a diminution of fluorescence, which is avoided with the present approach. However, the immunolabeling technique does present some limitations. For example, the method requires perfusion-fixed tissue, which is generally less optimal for in situ hybridization histochemistry than fresh frozen tissue that is subsequently fixed after sectioning. Also, the prolonged incubations involved in the immunocytochemical sequence can result in loss of cellular mRNA, presumably due to exposure to RNase activity. In addition, in the present double-labeling experiments, exposure of emulsion was not seen over neurons that were very densely immunoreactive for Fluoro-gold (Fig. 11B), even when hybridization times exceeded 24 hours. It remains unclear whether excessive DAB reaction product in these cells might inhibit access of the riboprobe, or, alternatively, present a barrier to emission, resulting in fewer detectable grains. In any case, these factors would likely have produced an underestimation of double-labeled cells and precluded a true quantitative analysis of the present material.

\section{Ventral subicular projections to the bed nucleus of the stria terminalis}

Axons of subicular origin arrive at the BST via at least two routes: 1) the fimbria-fornix pathway, including some fibers that detach from the most proximal part of the medial corticohypothalamic tract; and 2) the stria terminalis, including adjacent portions of the caudate putamen. The stria terminalis component of the subicular projection to the BST apparently arises as part of the ventral pathway described by Köhler ('90), which initially courses through the amygdala.

In general, fibers arriving at the BST via the fornix were concentrated within the rostral two-thirds of this structure, while those arriving through the stria terminalis were primarily directed to the caudal two-thirds. However, the systems could not be clearly separated, as fibers from both major pathways could be traced throughout the entire rostrocaudal extent of the BST. Perhaps the best example of convergence among these pathways was observed ventrally within the caudal portion of the BST (corresponding to the ventral part of the posterior intermediate division), where following PHA-L injections in the lateral portion of the ventral subiculum, axons continuous with the postcommissural fornix, the proximal portion of the medial corticohypothalamic tract, and the stria terminalis were intermingled, and elaborated a dense terminal plexus. It remains unclear whether fibers coursing within these systems arise from separate populations of subicular cells, or represent collaterals of individual neurons. Interestingly, experiments utilizing dual retrograde tracers have shown that some subicular neurons project to both the mammillary body and entorhinal cortex (Donovan and Wyss, '83). These structures represent targets of the fornix system (mammillary body), as well as the ventrolateral pathway leading to the stria terminalis (entorhinal cortex), indirectly suggesting the possibility of collateralization regarding projections to the BST, although this will need to be tested.

The present findings indicate that the ventral subiculum selectively innervates subnuclei of the BST. Thus, following PHA-L deposits within the ventral subiculum, densest labeling of fibers/terminals was consistently seen within the anterior medial, anterior lateral, ventral medial, and posterior intermediate subdivisions of the BST; in cases of 


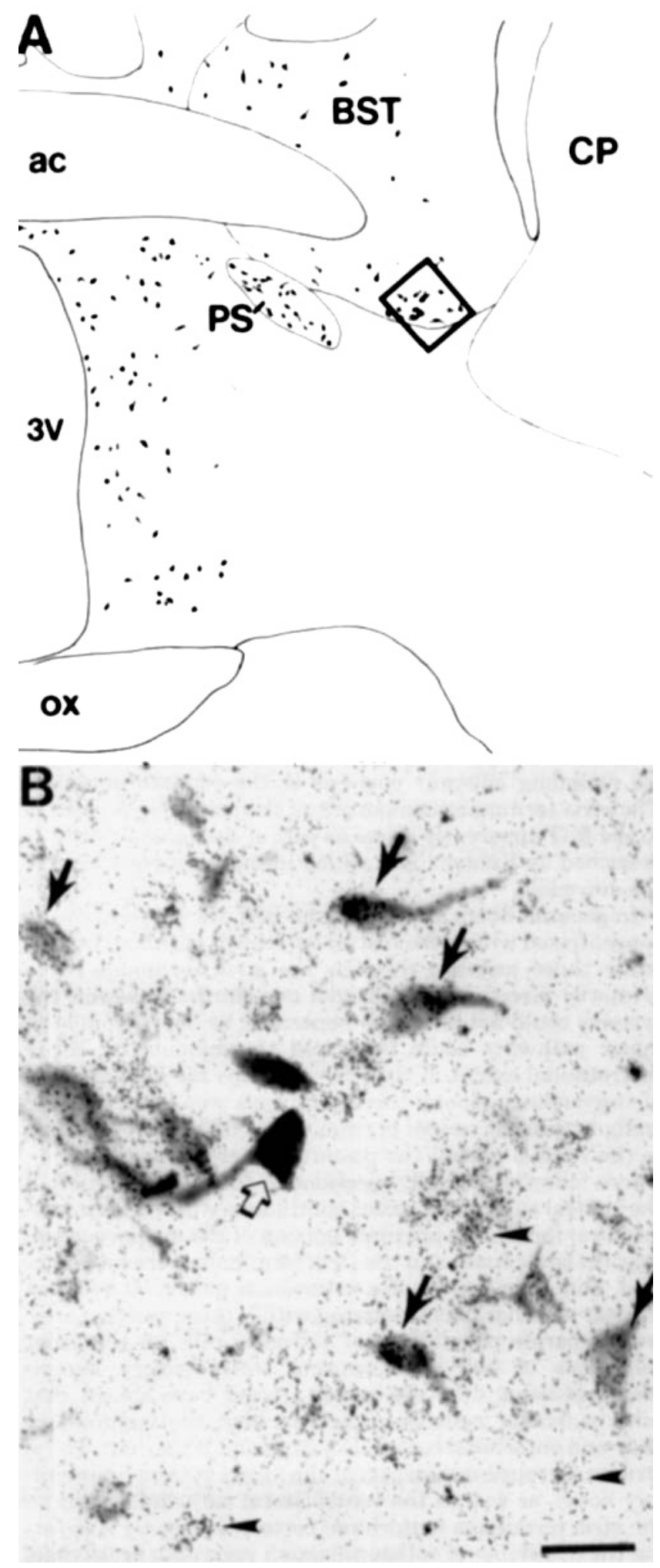

injections involving the lateral part of the ventral subiculum, labeling was also prominent within the preoptic division. Relatively light labeling was noted within the ventral lateral division and in the parastrial nucleus, and in all of the cases the dorsal lateral and posterior lateral divisions of the BST, as well as the posterior medial
Fig. 12. A: Camera lucida drawing depicting the distribution of neurons immunolabeled for Fluoro-gold following delivery of the tracer to the medial parvicellular PVN (case 30). This section was also processed for $\mathrm{GAD}_{67}$ in situ hybridization, and the boxed region (corresponding to the ventral lateral division) within the BST is shown in B. B: Fluoro-gold-immunolabeled neurons in the BST are shown following in situ hybridization for $\mathrm{GAD}_{67} \mathrm{mRNA}$. Some double-labeled cells are depicted by black arrows. Arrowheads denote cells that are labeled for GAD mRNA only. Open arrow indicates a heavily immunostained cell over which grains could not be detected. Scale bar $=50 \mu \mathrm{m}$.

division, were largely avoided. In contrast to the cases involving the ventral subiculum, injections placed in midportions of the amygdalohippocampal transition area also labeled the lateral BST subdivisions to some extent. Consistent with previous reports (Krettek and Price, '78; Swanson et al., ' 87 ), these projections apparently reached the BST exclusively through the stria terminalis.

The present data regarding the subicular projections to the BST are also of relevance to current concepts of basal forebrain organization. Many authors have noted similarities between the BST and the central and medial nuclei of the amygdala in terms of morphology, neurochemistry, and connectivity (de Olmos, '72; Hopkins and Holstege, '78; Krettek and Price, '78; Loewy and McKellar, '80; Saper and Loewy, '80; Roberts et al., '82; McDonald, '83; Woodhams et al., '83; Holstege et al., '85; Gray and Magnuson, '87; Alheid and Heimer, '88; Grove, '88) and indeed, the BST and centromedial amygdala have long been proposed to form an anatomic continuum (Johnston, '23). These and other recent observations have led to the re-emergence of this concept, termed the "extended amygdala" (de Olmos et al., '85; Alheid and Heimer, '88; de Olmos, '90), which defines: 1) a central division or group consisting of the lateral BST, central amygdaloid nucleus, and intervening anterodorsal portion of the SI; and 2) a medial component comprised of the medial segments of the BST, medial amygdaloid nucleus, and interposed posteroventral part of the SI. The central division or group has been most closely associated with autonomic functions in view of its prominent projections to brainstem autonomic centers such as the nucleus of the solitary tract and parabrachial nuclei; the medial division has been implicated in neuroendocrine functions, based primarily on its extensive interconnections with mediobasal hypothalamic regions. In the present PHA-L tracing studies, dense ventral subicular inputs to medial portions of the BST (with the exception of the posterior medial division of Moga et al., '89) and amygdala were revealed, as well as an innervation of the intervening portion of the SI. Interestingly, these projections avoided portions of the lateral group, particularly the dorsal lateral and posterior lateral BST subdivisions, as well as the lateral division of central nucleus of the amygdala. The present data reinforce the extended amygdala concept on connectional grounds, and suggest that the ventral subiculum is preferentially affiliated with its medial division. Consideration of the hippocampal connections with respect to this continuum, particularly its medial division, may ultimately be important to understanding hippocampal influences on the HPA axis.

\section{The BST as a relay for hippocampal influences on the PVN}

The present PHA-L/Fluoro-gold double-labeling experiments suggest that subicular fibers may contact PVNprojecting neurons in the $\mathrm{BST}$, and that these inputs are 
likely to occur predominantly within specific BST subregions. Following PHA-L injections in the ventral subiculum and Fluoro-gold deposits in the ipsilateral PVN, PHA-Llabeled terminals were seen at high magnification in direct apposition to Fluoro-gold-labeled cells or proximal dendritic segments within the anterior medial, ventral medial, and posterior intermediate divisions of the BST, i.e., the BST subnuclei containing the densest terminal networks as well as the majority of retrogradely labeled neurons. Such appositions were occasionally detected within the anterior lateral and ventral lateral BST divisions, and the parastrial nucleus. In some cases, PHA-L-labeled terminals abutting Fluoro-gold labeled neurons were seen in the form of pericellular basket arrangements highly suggestive of synaptic input, although these were noted relatively infrequently. In any case, the synaptic nature of appositions between subicular fibers and PVN-projecting neurons in the BST will require confirmation at the electron microscopic level. Also, the extent to which subicular terminals approximate dendrites of BST neurons will need to be addressed, and could not be examined using the present method. In view of the fact that the dendrites of BST neurons may extend for considerable distances, particularly those of neurons within the medial BST (McDonald, '83), it is possible that subicular fibers might contact dendrites of cells residing in neighboring subdivisions. This would appear to be less likely for neurons within the lateral portions of the BST, whose dendrites extend for more limited distances (McDonald, '83).

The present in situ hybridization data suggest that a high percentage of neurons in the BST utilize the neurotransmitter GABA. In addition, the combined Fluoro-gold/ $\mathrm{GAD}_{67}$ in situ hybridization studies indicate that a proportion of the BST projection to the PVN is GABAergic. Using the present protocol, transcripts encoding GAD mRNA could be detected in approximately half of Fluoro-gold-immunolabeled neurons within the BST. However, due to a number of technical limitations noted above, the GABAergic nature of the BST projection to the PVN is likely to have been underestimated using the present approach. Clearly, resolution of this question will require development and application of a more sensitive double-labeling protocol. In addition, it has recently been demonstrated that GAD exists in two isoforms (Erlander et al., '91), and that both are apparently present in GABA neuronal populations examined to date, although their respective levels of expression may vary (Esclapez et al., '91; Mercugliano et al., '92). While the present experiments utilized a probe directed at the $M_{r} 67,000$ form of GAD, it is possible that future investigations may benefit from the use of probes specific for both the $M_{r} 67,000$ and $M_{r} 65,000$ isoforms.

\section{Functional implications}

Numerous studies have implicated the hippocampus in the inhibitory control of the HPA axis (see opening paragraphs). Although evidence for some direct hippocampal innervation of the PVN has been reported (Kiss et al., '83), anterograde tracing experiments have suggested that hippocampal projections to this region are directed primarily to the periphery of the nucleus. Prior evidence has also indicated that the dendrites of PVN neurons remain largely confined to the nucleus itself (Van Den Pol, '82; Swanson and Sawchenko, '83; Rho and Swanson, '89), suggesting a limited potential for direct interaction between hippocampal and PVN neurons. Moreover, the output of the hippocampus is thought to be excitatory, primarily utilizing glutamate as a neurotransmitter (Walaas and Fonnum, '80; Finch et al., '86). These findings suggest that inhibitory hippocampal influences on the mpPVN are likely to occur through one or more intervening synapses. In accordance with the view of the subiculum as a principal hippocampal output structure, the present results suggest that hippocampal influences on the mpPVN neurons may be mediated, at least in part, through a relay in the BST.

The present studies also suggest that a significant proportion of the BST projection to the mpPVN is likely to involve the neurotransmitter GABA, and, taken together with the anterograde tracing data, are consistent with an excitatory subicular projection to BST cells, which in turn could inhibit activity of PVN neurons. These findings are interesting in view of studies that have implicated GABAergic mechanisms in the negative control of HPA function. For example, intracerebroventricular infusion of GABA has been shown to inhibit $\mathrm{CRH}$ release into the portal circulation (Plotsky et al., '87b), as well as to inhibit ACTH secretion (Makara and Stark, '74), and similar delivery of a selective GAD inhibitor was reported to reduce the effect of dexamethasone on basal and stress-induced ACTH secretion (Acs and Stark, '78). In addition, in vitro studies have demonstrated GABA inhibition of basal CRH secretion (Jones et al., '76), as well as the ability of GABA to antagonize serotonin and acetylcholine-induced $\mathrm{CRH}$ release (Calogero et al., '88; Hillhouse and Milton, '89). Also, immunocytochemical studies support a very prominent GABAergic innervation of the PVN, including ultrastructural evidence of GABAergic innervation of CRH-containing neurons (Tappaz et al., '83; Mugnani and Oertel, '85; Olschowka, '87; Decavel and Van Den Pol, '90, '92).

While the inhibitory influences of the hippocampus on HPA function may be explained in part by the subiculumBST-PVN pathway described here, the possibility exists for alternative regulation pathways. For example, a number of other forebrain regions appear to be in a position to mediate a monosynaptic relay between the subiculum and PVN. These include the anterior hypothalamic area, medial preoptic area, dorsomedial hypothalamic nucleus, ventromedial hypothalamic nucleus, ventral premammillary nucleus, supramammillary nucleus, rostromedial zona incerta, and medial amygdaloid nucleus, all of which are known to receive subicular afferents, and have been reported to project to the PVN (Conrad and Pfaff, '76; Meibach and Siegel, '77; Swanson and Cowan, '77; Palkovits and Záborszky, '79; Silverman et al., '81; Berk and Finkelstein, '81; Tribollet and Dreifuss, '81; Sawchenko and Swanson, '83a; Ter Horst and Luiten, '86; Luiten et al., '87; Köhler, '90; Witter and Groenewegen, '90). Although not the focus of the present investigation, many of these regions were found to contain at least some retrogradely labeled cells that were approximated by terminals of subicular origin; interestingly, the majority of these regions are also known to contain prominent populations of GABAergic neurons. It should be noted, however, that data from lesion studies have argued against such a role for a number of these areas, at least in the tonic regulation of $\mathrm{CRH} / \mathrm{AVP}$ neurons (Herman et al., '90, '92). In addition to alternative monsynaptic pathways, hippocampal influences on HPA activity may involve multisynaptic circuits, of which numerous possibilities exist, including connections in medial hypothalamic regions, the lateral septum, and amygdala, as well as the BST. There have also been suggestions from the literature that different portions of the hippocampal formation and BST may have differential effects on HPA activity 
(Dunn and Orr, '84; Dunn, '87). Clearly, further precise anatomical and physiological data are needed in order to disclose the extent and functional impact of neuronal circuits mediating hippocampal influences on the HPA axis. In view of the present anatomical data, it has become increasingly evident that the multiple pathways utilized by subicular efferents en route to the basal forebrain will need to be considered in the design of such experiments.

\section{CONCLUSIONS}

The significance of a BST relay for hippocampal influences on the PVN is presently unclear, and may be related to any of several aspects of HPA function. Lesion experiments have pointed toward a role for the hippocampus in the tonic regulation of $\mathrm{CRH} / \mathrm{AVP}$ neurons within the mpPVN (Herman et al., '89b, '92). Other studies have implicated this structure in the well-described circadian fluctuations in HPA activity (Slusher, '66; Moberg et al., '71; Fischette et al., '80, '81; Reul et al., '87; Ratka et al., '89), as well as in steroid-mediated negative feedback (Feldman and Conforti, '80; Sapolsky et al., '84, '90; Margariños et al., '87; Plotsky et al., '87a). It is also possible that BST neurons receiving subicular input might encode aspects of learning in the context of stress responsiveness. Moreover, these possibilities may not be mutually exclusive, and distinguishing among possible effects poses a formidable challenge for future experiments, particularly in view of the fact that the BST has been increasingly recognized as a site of convergence of stress-related information (Henke, '84; Feldman et al., '90; Casada and Dafny, '92). Future multidisciplinary experiments may provide further insight into the role of the BST in the regulation of the HPA axis.

\section{ACKNOWLEDGMENTS}

The authors acknowledge the invaluable assistance of Sharon Burke and John Valdes. The $\mathrm{GAD}_{67}$ clone was the gift of Dr. A. Tobin (UCLA). The Fluoro-gold antibody was generously supplied by Dr. H.T. Chang (University of Tennessee). We also thank Dr. Peter C. Brunjes and Dr. László Záborszky for reviewing this manuscript. This work was supported by grants 5T 32DK07245 (W.E.C.), NS08267 (J.P.H.), DA00265-12, and MH42251-06 (S.J.W.).

\section{LITERATURE CITED}

Acs, Z., and E. Stark (1978) Possible role of gamma-aminobutyric acid synthesis in the mechanism of dexamethasone feedback action. J. Endocrinol. 77:137-141.

Alheid, G.F., and L. Heimer (1988) New perspectives in basal forebrain oryanization of special relevance to neuropsychiatric disorders: The striatopallidal, amygdaloid, and corticopetal components of substantia innominata. Ncuroscience 27:1-39.

Arriza, J.L., R.B. Simerly, L.W. Swanson, and R.M. Evans (1988) Neuronal mineralocorticoid receptor as a mediator of glucocorticoid response. Neuron. 1:887-900

Berk, M.L., and J.A. Finkelstein (1981) Afferent projections to the preoptic area and hypothalamic regions in the rat brain. Neuroscience $6: 1601-$ 1624.

Calogero, A.E., W.T. Galluci, G.P. Chrousos, and P.W. Gold (1988) Interaction between GABAergic neurotransmission and rat hypothalamic corticotropin-releasing hormone secretion in vitro. Brain Res. 463.28-36.

Casada, J.H, and N. Dafny (1992) Evidence for two different afferent pathways carrying stress-related information (noxious and amygdala stimulation) to the bed nucleus of the stria terminalis. Brain Res. 579:93-98.
Chang, H.T., Kuo, J.A. Whittaker, and N.G. Cooper (1990) Light and electron microscopic analysis of projection neurons retrogradely labeled with Fluoro-gold: Notes on the application of antibudies to Fluoro-gold. J. Neurosci. Methods 1:31-37.

Conrad, L.C.A., and D.W. Pfaff (1976) Efferents from medial basal forebrain and hypothalamus in the rat. J. Comp. Neurol. 169:185-220.

Decavel, C., and A.N. Van Den Pol (1990) GABA: A dominant neurotransmitter in the hypothalamus. J. Comp. Neurol. 302:1019-1037.

Decavel, C., and A.N. Van Den Pol (1992) Converging GABA- and glutamate immunoreactive axons make synaptic contact with identified hypotha lamic neurosecretory neurons. J. Comp. Neurol. 316:104-116

de Oimos, J.S. (1972) The amygdaloid projection field in the rat as studied with the cupric-silver method. In B.E. Elefteriou (ed): The Neurobiology of the Amygdala. New York: Plenum, pp. 145-204.

de Olmos, J.S. (1990) The amygdala. In G. Paxinos (ed): The Human Nervous System. New York: Academic Press, pp. 583-710.

de Olmos, J.S., G.A. Alheid, and C.A. Beltramino (1985) Amygdala. In G Paxinos (ed): The Rat Nervous System. New York: Academic Press, pp 223-334.

Donovan, M.K., and J.M. Wyss (1983) Evidence for some collateralization between cortical and diencephalic efferent axons of the rat subicular cortex. Brain Res. 259:181-192.

Dunn, J. (1987) Plasma corticasterone responses to electrical stimulation of the bed nucleus of the stria terminalis. Brain Res. 407:327-331.

Dunn, J.D. and S.E. Orr (1984) Differential plasma corticosterone responses; to hippocampal stimulation. Exp. Brain Res. 54:1-6.

DuPont, A., E. Bastarache, E. Endroczi, and C. Fortier (1972) Effect of hippocampal stimulation on plasma thryotropin (THS) and corticoste.rone responses to acute cold exposure in the rat. Can. J. Physiol Pharmacol. 50:364-367.

Endröczi, E., K. Lissak, B. Bohus, and S. Kovacs (1959) The inhibitory influence of archicortical structures on pituitary-adrenal function. Act: Physiol. Hung. 16:17-22.

Frlander, M.G., N.J.K. Tillakaratne, S. Feldblum, N. Patel, and A.J. Tobin (1991) Two genes encode distinct glutamale decarboxylases. Neuron 7:91-100.

Esclapez, M., N.J.K. Tillakaratne, A.J. Tobin, and C.R. Houser (1991) Detection of two forms of GAD and their mRNAs in rat brain by immunocytochemistry and non-radioactive in situ hybridization. Soc. Neurosci. Abstr. 17:416.

Feldman, S., and N. Conforti (1980) Participation of the dorsal hippocampus in the glucocorticoid feedback effect on adrenocortical activity. Neuroendocrinology 30:52-55.

Feldman, S., N. Conforti, and D. Saphier (1990) The preoptic area and bed nucleus of the stria terminalis are involved in the effects of the amygdala on adrenocortical secretion. Neuroscience 37:775-779.

Fendler, K., G. Karmos, and G. Telegdy (1961) The effect of hippocampal lesion on pituitary-adrenal function. Acts Physiol. (Budapest) 20:283297.

Ferraguti, F., M. Zoli, M. Arinsson, L.F. Agnati, M. Goldstein, D. Filer, and K. Fuxe (1990) Distribution of glutamic acid decarboxylase messenger RNA-containing nerve cell populations in the male rat brain. J. Chem. Neuroanat. 3:377-396.

Finch, D.M., E.E. Wong, E.L. Derian, and T.L. Babb (1986) Neurophysiology of limbic system pathways in the rat: Projections from the subicular complex and hippocampus to the entorhinal cortex. Brain Res. 397:205213.

Fischette, C.T., B.R. Komisaruk, H.M. Edinger, and A. Siegel (1980) Differential fornix ablations and the circadian rhythmicity of adrenal corticosteroid secretion. Brain Res, 195:373-387.

Fischette, C.T., H.M. Edinger, and A. Siegel (1981) Temporary desynchronization among circadian rhythms with lateral fornix tablation. Brain Res 229:85-101.

Gerfen, C.R., and P.E. Sawchenko (1984) An anterograde neuroanatomical tracing method that shows the detailed morphology of neurons, their axons and terminals: Immunohistochemical localization of an axonally transported plant lectin, Phaseolus vulgaris-leucoagglutinin (PHA-L). Brain Res. 290:219-238.

Gerfen, C., Sawchenko, P.E., and J. Carlsen (1989) The PHA-L anterograde axonal tracing method. In L. Heimer and L. Zaborszky (eds): Neuroanatomical Tract-Tracing Methods. 2. Recent Progress. New York: Plenum Press, pp. 19-47.

Gray, T.S., and D.J. Magnuson (1987) Neuropeptide neuronal efferents from the bed nucleus of the stria terminalis and central amygdaloid nucleus to the dorsal vagal complex in the rat. J. Comp. Neurol. 262:365-374. 
Groenewegen, H.J., E. Vermeulen-Van Der Zee, A. Te Kortschot, and M.P. Witter (1987) Organization of the projections from the subiculum to the ventral striatum in the rat. A study using the anterograde transport of Phaseolus vulgaris-leucoagglutinin. Neuroscience 23:103-120.

Grove, E.A. (1988) Neural associations of the substantia innominata in the rat: Afferent connections. J. Comp. Neurol. 277:315-346.

Henke, P.G. (1984) The bed nucleus of the stria terminalis and immobilization stress: Unit activity, escape behaviour, and gastric pathology in rats. Behav. Brain Res. 11:35-45.

Herman, J.P., P. Patel, H. Akil, and S.J. Watson (1989a) Localization and regulation of glucocorticoid and mineralocorticoid receptor messenger RNAs in the hippocampal formation of the rat. Mol. Endocrinol. 3:1886-1894.

Herman, J.P., M.K.-H. Schafer, E.A. Young, R. Thompson, J. Douglass, H. Akil, and S.J. Watson (1989b) Evidence for hippocampal regulation of neuroendocrine neurons of the hypothalamo-pituitary-adrenocortical axis. J. Neurosci. 9:3072-3082.

Herman, J.P., E.A. Young, A. Savina, and S.J. Watson (1989c) Hippocampalhypothalamic circuits mediating tonic inhibition of the hypothalamicpituitary-adrenal axis. Soc. Neurosci. Abstr. 19:135.

Herman, J.P., S.J. Wiegand, and S.J. Watson (1990) Regulation of basal corticotropin-releasing hormone and arginine vasopressin messenger ribonucleic acid expression in the paraventricular nucleus: Effects of selective hypothalamic deafferentations. Endocrinology 127:2408-2417.

Herman, J.P., W.E. Cullinan, E.A. Young, H. Akil, and S.J. Watson (1992) Selective forebrain fiber-tract lesions implicate ventral hippocampal structures in tonic regulation of paraventricular nucleus $\mathrm{CRH}$ and AVP mRNA expression. Brain Res. 592:228-238.

Hillhouse, E.W., and N.G.N. Milton (1989) Effect of noradrenaline and $\gamma$-aminobutyric acid on the secretion of corticotropin-releasing factor- 41 and arginine vasopressin from the rat hypothalamus in vitro. J. Endocrinol. 122:719-723.

Holstege, G., L. Meiners, and K. Tan (1985) Projections of the bed nucleus of the stria terminalis to the mesencephalon, pons, and medulla oblongata in the cat. Exp. Brain Res. 58:379-391.

Hopkins, D.A., and G. Holstege (1978) Amygdaloid projections to the mesencephalon, pons, and medulla oblongata in the cat. Exp. Brain Res. $32: 529-547$.

Hsu, S.M., and E. Soban (1982) Color modification of diaminobenzidene (DAB) precipitation by metallic ions and its application for double immunohistochemistry. J. Histochem. Cytochem. 30:1079-1082.

Itoh, Z., K. Akiva, S. Nakamura, N. Miguno, Y. Nakamura, and T. Sugimoto (1979) Application of coupled oxidation reaction to electron microscopic demonstration of horseradish peroxidase: Cobalt glucose oxidase method. Brain Res. 175:341-346.

Johnston, J.B. (1923) Further contributions to the study of the evolution of the forebrain. J. Comp. Neurol. 35:337-481.

Jones, M.T., E.W. Hillhouse, and J. Burden (1976) Effect of various putative neurotransmitters on the secretion of corticotropin-releasing hormone from the rat hypothalamus in vitro-a model of the neurotransmitters involved. J. Endocrinol. 69:1-10.

Ju, G., and L.W. Swanson (1989) Studies on the cellular architecture of the bed nuclei of the stria terminalis in the rat: I. Cytoarchitecture. J. Comp. Neurol. 280:587-602.

Ju, G., L.W. Swanson, and R.B. Simerly (1989) Studies on the cellular architecture of the bed nuclei of the stria terminalis in the rat: II. Chemoarchitecture. J. Comp. Neurol. 280:603-621.

Keller-Wood, M.E., and M.F. Dallman (1984) Corticosteroid inhibition of ACI'H secretion. Endocrinol. Rev. 5:1-24.

Kiss, J.Z., M. Palkovits, L. Záborszky, E. Tribollet, D. Szabó, and G.B. Makara (1983) Quantitative histological studies on the hypothalamic paraventricular nucleus in rats. II. Number of local and certain afferent nerve terminals. Brain Res. 265:11-20.

Knigge, K.M. (1961) Adrenocortical response to stress in rats with lesions of the hippocampus and amygdala. Proc. Soc. Exp. Biol. Med. 108:67-69.

Köhler, C. (1990) Subicular projections to the hypothalamus and brainstem: Some novel aspects revealed in the rat by the anterograde Phaseolus vulgaris leukoagglutinin (PHA-L) tracing method. Prog. Brain Res. 83:59-69.

Kovacs, K., J.Z. Kiss, and G.B. Makara (1986) Glucocorticoid implants around the hypothalamic paraventricular nucleus prevent the increase in corticotropin-releasing factor and arginine vasopressin immunostaining induced by adrenalectomy. Neuroendocrinology 44:229-234.

Krettek, J.E., and J.L. Price (1978) Amygdaloid projections to subcortical structures within the basal forebrain and brainstem in the rat and cat. J. Comp. Neurol. 178:225-254.
Loewy, A.D., and S. McKellar (1980) The neuroanatomic basis of central cardiovascular control. Fed. Proc. 39:2495-2503.

Luiten, P.G.M., G.J. Ter Horst, and A.B. Steffens (1987) The hypothalamus, intrinsic connections and outflow pathways to the endocrine system in relation to the control of feeding and metabolism. Prog. Neurobiol. $28: 1-54$.

Makara, G.B., and E. Stark (1974) Effect of gamma-aminobutyric acid (GABA) and GABA antagonist drugs on ACTH release. Neuroendocrinolgoy 16:178-190.

Mandell, A.J., L.F. Chapman, R.W. Rand, and R.D. Walter (1962) Plasma corticosteroids: Changes in concentration after stimulation of hippocampus and amygdala. Science 139:1212.

Margariños, A.M., G. Somoza, and A.F. DeNicola (1987) Glucocorticoid negative feedback and glucocorticoid receptors after hippocampectomy in rats. Horm. Metab. Res. 19:105-109.

McDonald, A.J. (1983) Neurons of the bed nucleus of the stria terminalis: A Golgi study in the rat. Brain Res. Bull. 10:111-120.

McEwen, B.S., J.M. Weiss, and L.S. Schwartz (1968) Selective retention of corticosterone by limbic structures in rat brain. Nature 220:911--912.

Meibach, R.C., and A. Siegel (1977) Efferent connections of the hippocampal formation in the rat. Brain Res. 124:197-224.

Mereugliano, M., J.J. Soghomonian, Y. Qin, H.Q. Nguyen, S. Feldblum M.G. Erlander, A.J. Tobin, and M.-F. Chesselet (1992) Comparative distribution of messenger RNAs encoding glutamic acid decarboxylases $\left(M_{r} 65,000\right.$ and $\left.M_{r} 67,000\right)$ in the basal ganglia of the rat. J. Comp. Neurol. 318:245-254.

Moberg, G.P., U. Scapagnini, J. de Groot, and W.F. Ganong (1971) Effect of sectioning the fornix on diurnal fluctuation in plasma corticosterone levels in the rat. Neuroendocrinology 7:11-15.

Moga, M.M., C.B. Saper, and T.S. Gray (1989) Bed nucleus if the stria terminalis: Cytoarchitecture, immunocytochemistry, and projection to the parabrachial nucleus in the rat. J. Comp. Neurol. 283:315-332.

Mugnani, E., and W.H. Oertel (1985) An atlas of the distribution of GABAergic neurons and terminals in the rat CNS as revealed by GAD immunohistochemistry. In A. Bjorklund and T. Hokfelt (eds): Handbook of Chemical Neuroanatomy, Vol. 4. GABA and Neuropeptides in the CNS, Part I. Amsterdam: Elsevier, pp. 436-622.

Novotny, G.E.K. (1977) A direct ventral connection between the bed nucleus of the stria terminalis and the amygdaloid complex in the monkey. $J$. Hirnforsch. 18:271-284.

Olschowka, J.A. (1987) GABAergic innervation of corticotropin releasing factor neurons in the rat paraventricular nucleus: An electron microscopic immunocytochemical study. Soc. Neurosci. Abstr. 460:15.

Palkovits, M., and L. Záborszky (1979) Neural connections of the hypothalamus. In P.J. Morgane and J. Panksepp (eds): Handbook of the Hypothalamus, Vol. 1. Anatomy of the Hypothalamus. New York: Dekker, pp. 379-509.

Paxinos, G., and C. Watson (1986) The Rat Brain in Sterotaxic Coordinates, 2nd ed. Sydney: Academic Press.

Plotsky, P.M., S. Otto, and R.M. Sapolsky (1987a) Inhibition of immunoreactive corticotropin-releasing factor secretion into the hypophysial-portal circulation by delayed glucoroticoid feedback. Endocrinology 119:11261130.

Plotsky, P.M., S. Otto, and S. Sutton (1987b) Neurotransmitter modulation of corticotropin releasing factor secretion into the hypophyseal-portal circulation. Life Sci. 41:1311-1317.

Ratka, A., W. Sutanto, M. Bloemers, and E.R. deKloet (1989) On the role of brain mineralocorticoid (type I) and glucocorticoid (type II) in neuroendocrine regulation. Neuroendocrinology 50:117-123.

Reul, J.M.H.M., and E.R. de Kloet (1985) Two receptor systems for corticosterone in rat brain: Microdistribution and differential occupation. Endocrinology 117:2502-2511.

Reul, J.M.H.M., and E.R. de Kloet (1986) Anatomical resolution of two types of corticosterone receptor sites in rat brain with in vitro autoradiography and computerized image analysis. J. Steroid Biochem. 24:269-272.

Reul, J.M.H.M., F.R. Van Den Bosch, and E.R. de Kloet (1987) Relative occupation of type-I and type-II corticosteroid receptors in rat brain following stress and dexamethasone treatment: Functional implications. J. Endocrinol. 115:459-467.

Rho, J.-H., and L.W. Swanson (1989) A morphometric analysis of functionally defined subpopulations of neurons in the paraventricular nucleus of the rat with observations on the effects of colchicine. J. Neurosci. 9:1375-1388.

Roberts, G.W., P.L. Woodhams, J.M. Polak, and T.J. Crow (1982) Distribution of neuropeptides in the limbic system of the rat: The amygdaloid complex. Neuroscience 7:99-131. 
Rubin, R.T., A.J. Mandell, and P.H. Crandall (1966) Corticosteroid responses to limbic stimulation in man: Localization of stimulus sites. Science 153:767-768

Saper, C.B., and A.D. Loewy (1980) Efferent projections of the parabrachial nucleus in the rat. Brain Res. 197:291-317.

Saphier, D., and S. Feldman (1987) Effects of septal and hippocampal stimuli on paraventricular neurons. Neuroscience 20:740-755.

Sapolsky, R.M., B.S. McEwen, and T.C. Rainbow (1983) Quantitative autoradiography of ${ }^{3} \mathrm{H}$-corticosterone receptors in rat brain. Brain Res. $271: 331-334$

Sapolsky, R.M., L.C. Krey, and B.S. McEwen (1984) Glucocorticoid-sensitive hippocampal neurons are involved in terminating the adrenocortical stress response. Proc. Natl. Acad. Sci. USA 81:6174-6177.

Sapolsky, R.M., M.P. Armanini, S.W. Sutton, and P.M. Plotsky (1989) Elevations of hypophyseal portal concentrations adrenocorticotropin secretagogues after fornix transection. Endocrinology 125:2881-2887.

Sapoisky, R.M., M.P. Armanimi, D.R. Packan, S.W. Sutton, S.W., and P.M. Plotsky (1990) Glucocorticoid feedback inhibition of adrenocorticotropic hormone secretagogue release. Neuroendocrinology 51:328-336.

Sawchenko, P.E. (1987) Evidence for a local site of actions for glucocorticoids in inhibiting CRF and vasopressin expression in the paraventricular nucleus. Brain Res. 403:213-224.

Sawchenko, P.E., and L.W. Swanson (1983a) The organization of forebrain afferents to the paraventricular and supraoptic nuclei of the rat. J. Comp. Neurol. 218:121-144.

Sawchenko, P.E., and L.W. Swanson (1983b) The organization and biochemical specificity of afferent projections to the paraventricular and supraoptic nuclei. Prog. Brain Res. 60:19-29.

Sehmued, L.C. ( 1990) Fluoro-gold and 4-acetyamido-4'-isothiocyanostilbene2,2 -disulfonic acid: Use of substituted stilbenes in neuroanatomical studies. In P.M. Conn (ed): Methods in Neurosciences, Vol. 3. New York: Academic, pp. 317-330.

Schmued, L.C., and J.H. Fallon (1986) Fluoro-gold: A new fluoroscent retrograde axonal tracer with numerous unique properties. Brain Res. $377: 147-154$

Silverman, A.J., D.L. Hoffman, and E.A. Zimmerman (1981) The descending afferent connections of the paraventricular nucleus of the hypoathalamus. Brain Res. Bull. 6:47-61

Simerly, R.B., and L.W. Swanson (1988) Projections of the medial preoptic nucleus: A Phaseolus vulgaris leucoagglutinin anterograde tract-tracing study in the rat. J. Comp. Neurol. 270:209-242.

Slusher, M.A. (1966) Effects of cortisol implants in the brainstem and ventral hippocampus on diurnal corticosteroid levels. Exp. Brain Res. 1:184-194.

Sousa, R.J., N.H. Tannery, and E.M. Lafer (1989) In silu hybridization mapping of glucocorticoid receptor messenger ribonucleic acid in rat brain. Mol. Endocrinol. 3:481-494.

Swanson, L.W. (1986) Organization of mammalian neuroendocrine system. In V.B. Mountcastle, F.E. Bloom, and S.R. Geiger (eds): Handbook of Physiology, Vol. IV. Baltimore: Waverly Press, pp. 317-363.

Swanson, L.W., and W.M. Cowan (1977) An autoradiographic study of the organization of the efferent projections of the hippocampal formation in the rat. J. Comp. Neurol. 172:49-84
Swanson, L.W., and W.M. Cowan (1979) The connections of the septal region in the rat. J. Comp. Neurol. 186:621-656.

Swanson, L.W., and P.E. Sawchenko (1983) Hypothalamic integration: Organization of the paraventricular and supraoptic nuclei. Annu. Rev. Neurosci. 6:269-324.

Swanson, L.W., C. Köhler, and A. Björklund (1987) The limbic region. I. Septohippocampal system. In A. Björklund, T. Hökfelt, and I.W. Swanson (eds): Handbook of Chemical Neuroanatomy, Vol. 5: Integrated Systems of the CNS, Part I. Amsterdam: Elsevier, pp. 125-275.

Tappaz, M.L., W.H. Oertel, M. Wassef, and E. Mugnani (1982) Central GABAergic neuroendocrine regulations: Pharmacological and morphological evidence. Prog. Brain Res. 55:77-96.

Tappaz, M.L., M. Wassef, W.H. Oertel, L. Paut, and J.F. Pujol (1983) Lightand electron-microscopic immunocytochemistry of glutamic acid decarboxylase (GAD) in the basal hypothalamus: Morphological evidence for neuroendocrine $\gamma$-aminobutyrate (GABA). Neuroscience 9:271-287.

Ter Horst, G.J., and P.G.M. Luiten (1986) The projections of the dorsomedial hypothalamic nucleus in the rat. Brain Res. Bull. 16:231-248.

Tribollet, E., and J.J. Dreifuss (1981) Localization of neurones projecting to the hypothalamic paraventricular nucleus area of the rat: A horseradish peroxidase study. Neuroscience 6:1315-1328.

Van Den Pol, A.N. (1982) The magnocellular and parvocellular paraventricu. lar nucleus of rat: Intrinsic organization. J. Comp. Neurol. 206:317-345.

Van Eeckelen, J.A.M., W. Jiang, E.R. de Kloet, and M.C. Bohn. (1988) Distribution of the mineralocorticoid and glucocorticoid receptor mRNA. in the rat hippocampus. I. Neurosci. Res. 21:88-94.

Walaas, I., and F. Fonnum (1980) Biochemical evidence for glutamate as a transmitter in hippocampal efferents to the basal forebrain and hypothalamus in the rat brain. Neuroscience 5:1691-1698.

Weller, K.L., and D.A. Smith (1982) Afferent connections to the bed nucleus of the stria terminalis. Brain Res. 232:255-270.

Wilson, M.M., S.E. Greer, M.A. Greer, and L. Roberts (1980) Hippocampal inhibition of pituitary-adrenocortical function in female rats. Brain Res. 197:433-441.

Witter, M.P., and H.J. Groenewegen (1990) The subiculum: Cytoarchitectonically a simple structure, but hodologially complex. Prog. Brain Res. 83:47-58.

Woodhams, P.L., G.W. Roberts, J.M. Polak, and T.J. Crow (1983) Distribution of neuropeptides in the limbic system of the rat: The bed nucleus of the stria terminalis, septum, and preoptic area. Neuroscience 8:677-703.

Note added in proof: Since the submission of this manuscript, a detailed account of the projections of a portion of the ventral subiculum has been published (Canteras and Swanson, '92, J. Comp. Neurol, 324:180-194). This study, which also involved the use of the PHA-L method, focused on the projections of ventral subicular neurons located predominantly medial (toward the temporal pole) to those cases described here. While numerous similarities are evident in the projection patterns of the cases described in the two studies, some interesting differences are evident and generally point toward a differential topography that is organized according to the mediolateral (or temporoseptal) position of ventral subicular neurons. 